13) Schumacher, P. (2009). Parametricism: A New Global Style for Architecture and Urban Design. AD Architectural Design - Digital Cities.

14) Toudert, F. A. (2005). Dependence of Outdoor Thermal Comfort on Street Design in Hot and Dry Climate. Berichte des Meteorologischen Institutes der Universität Freiburg. Retrieved from https://www.meteo.unifreiburg.de/forschung/publikationen/berichte/report15.pdf

15) Wang, J. (2010). Parametric design based on building information modeling for sustainable buildings. the IEEE 2010 International Conference on Challenges in Environmental Science and Computer Engineering, 236-239.

16) Woodbury. (2017). Interactive design galleries: A general approach to interacting with design alternatives. Design Studies, Vol. 52.

17)(n.d.). Retrieved from https://archello.com/project/kartal-pendik-masterplan

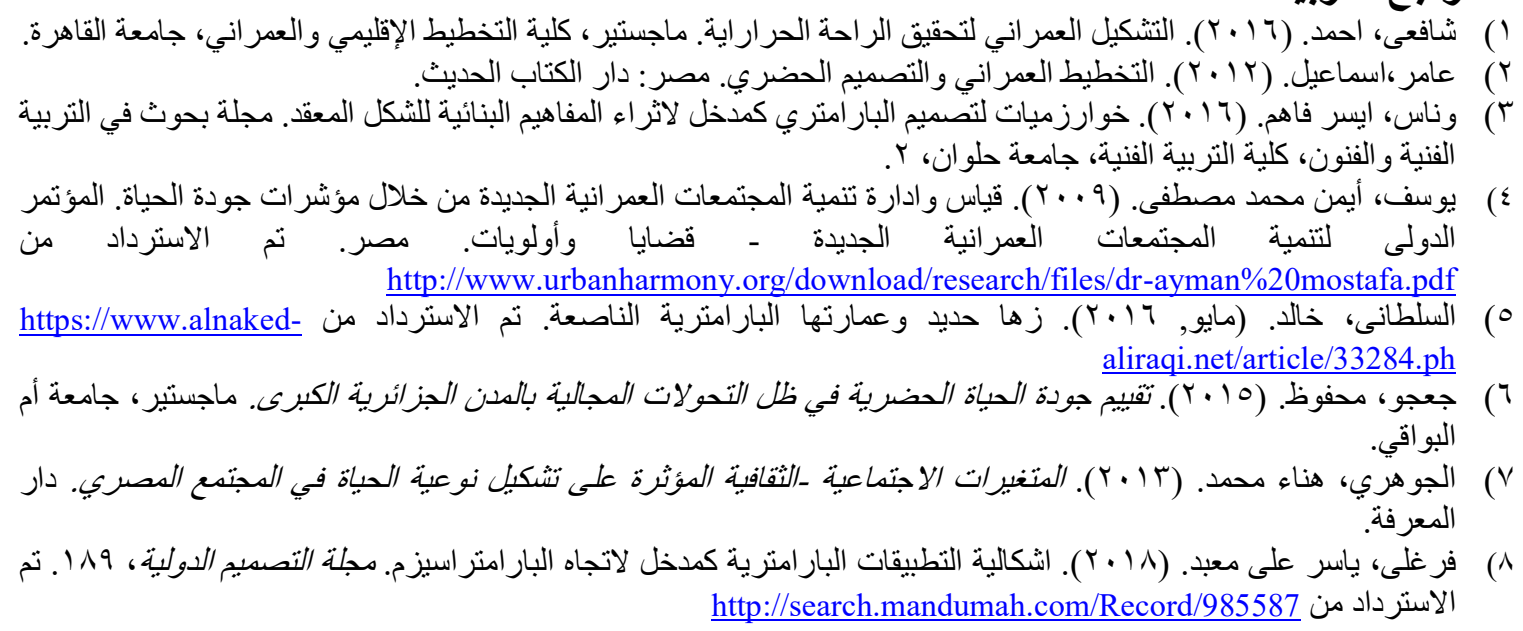


تطبيق البرمجيات البار امترية لقياس الراحة الحرارية للفر اغات العمر انية لتحسين مؤشرات جودة الحياة البيئية

ت. درجة حرارة الاشعاع Mean radiant temperature (Tmrt)
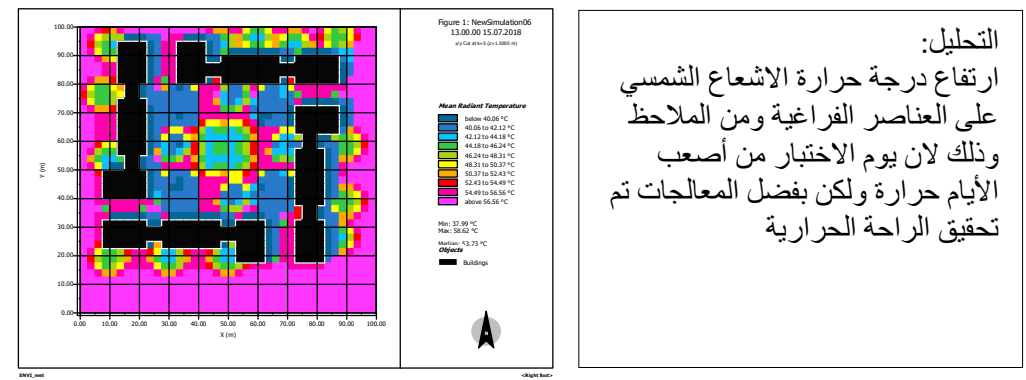

ث. الرطوبة النسبية Relative humidity (RH)
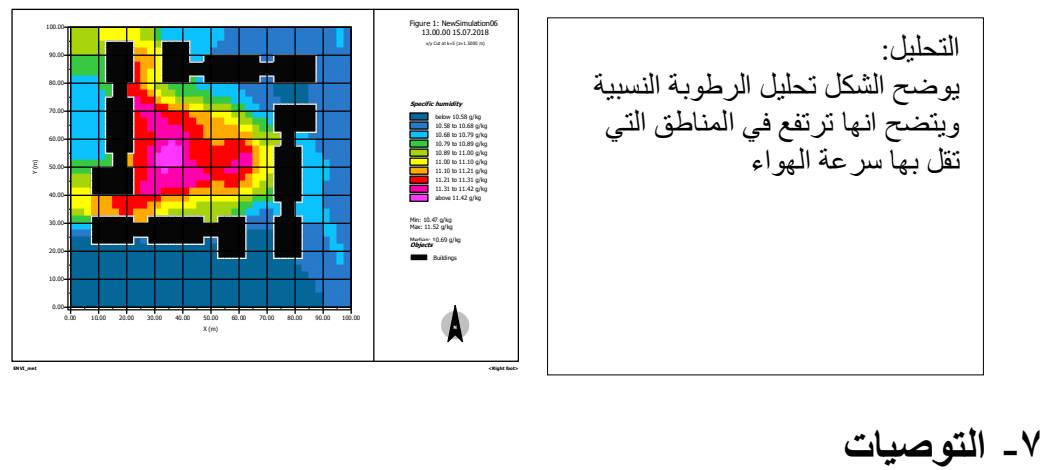

- يقدم البحث منهجية للتقييم الرقمى ومدى دقة نتائجها لذلك يوصي بتطبيق منهجية التصميم البارمترى على باقى مؤشرات

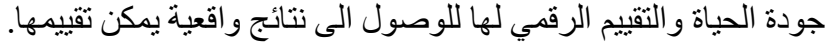

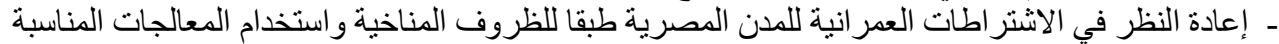

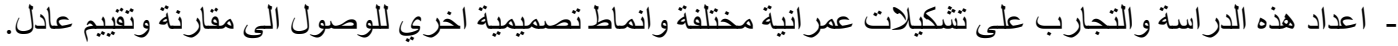

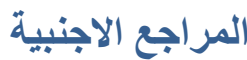

1) Aish, R. a. (2017). Comparative evaluation of parametric design systems for teaching design computation. Design Studies, Vol. 52.

2) Ariane, S. A. (2012). Neighborhood Urban Quality of Life Guidelines for Urban Planning and Development of New Assessment Tool. Faculty of Engineering, Cairo University.

3) ASHRAE. (2004). Thermal Environmental Conditions for Human Occupancy. Retrieved from http://www.almasesepahan.com/fh/download/ASHRAE_Thermal_Comfort_Standard.pdf

4) Beatley, S. W. (2009). The Sustainable Urban Development Reader. second edition, Routledge, London and New York.

5) Bobek, M. a. (2015). Chapter 5 Measuring Urban Development and City Performance. In Perspectives on Business and Management. R.F https://www.intechopen.com/books/perspectives-onbusiness-and-management/measuring-urban-development-and-city-performance

6) Chokhachian, A. (2014). Studies on Architecture Design Procedure A Framework for Parametric Design Thinking. MSc. Thesis in Architecture Eastern .

7) Dino. (2012). Creative Design Exploration by Parametric Generative Systems In Architecture. METU JFA .

8) Europeancommission. (2015). IN-DEPTH REPORT Indicators for Sustainable Cities,. Science for Environment Policy.

9) Feist, S. (2016). A-BIM: Algorithmic-based Building Information Modelling. MSc. Thesis, ,Tecnico Lisboa,.

10) Hadid, Z. (2010, september). Sunrise Tower in Kuala Lumpur. Retrieved from http://www.evolo.us/architecture/sunrise-tower-in-kuala-lumpur-zaha-hadid/

11) Harding. (2017). Meta-Parametric Design. Design Studies Vol. 52.

12) Jabi, W. (2013). Parametric design for Architecture. London: Laurence King Publishing. 


\section{7-}

كما تم توضيحه سابقا في طريقة العمل داخل المصفوفة حيث تم اتباع طريقة التسلسل التر اكمي للتحليل واستخر اج النتائج

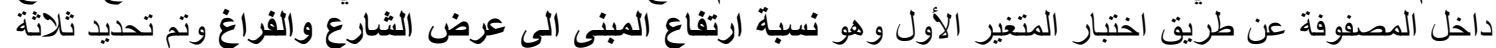

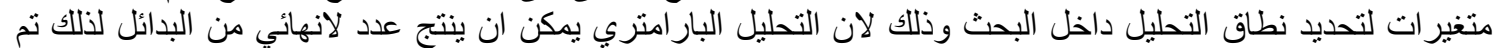

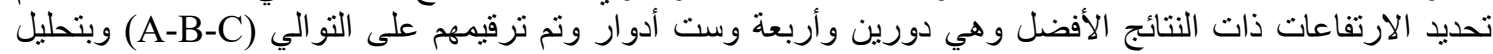

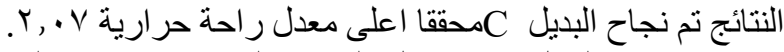

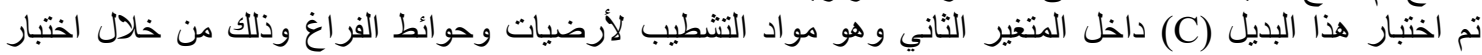

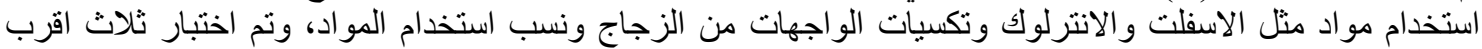
نتائج وتم ترقيمهم على النحو التالي C2-C2-C2 واظهرت النتائج ان الفضل ولن البدائل هو البديل C3 محققا راحه حرارية $1, \lambda r$ تم ادراج هذا البديل (C3) داخل المصفوفة الافقية للتحليل بالمتغير الثالث وهو نسب مسطحات المناطق الخضراء

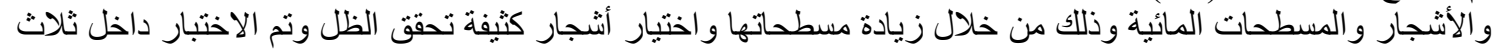

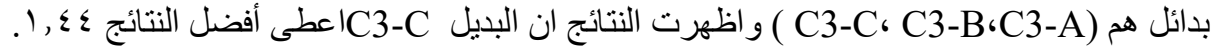

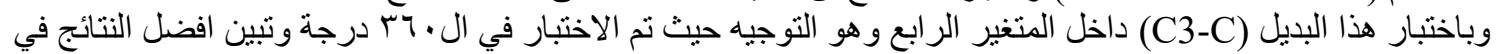

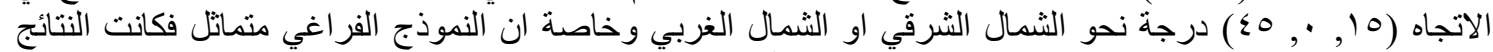

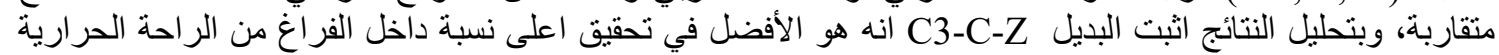

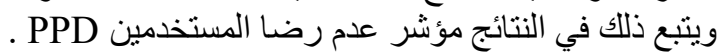

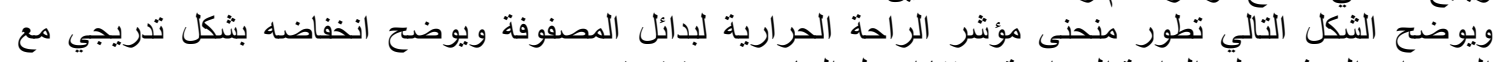

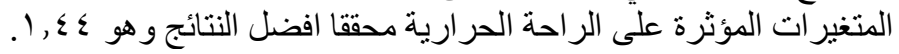

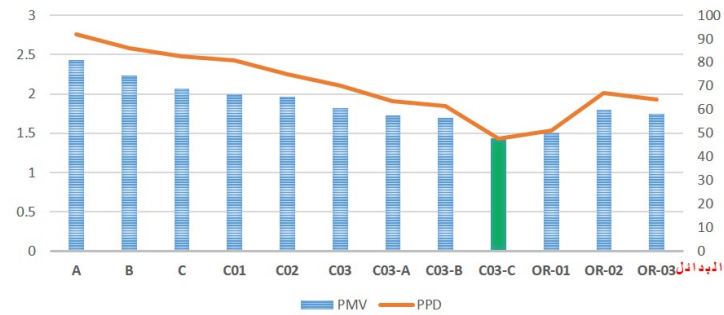

شكل ( • () تطور منحنى الراحة الحرارية ونسبة رضا المستخمين للبدائل الفراغية من خلال المعالجات البيئية

تحليل مخرجات مؤشر الراحة الحرارية للبديل الامثل (العوامل المل المناخية)

ENVI- يعتمد مؤشر الراحة الحر ارية على الأربع عو امل مناخية التي تم توضيحها سابقا وفيما يلى نتائج التحليل داخلية MET

Ambient Air Temperature (Ta) درجة حرارة الهواربة: .

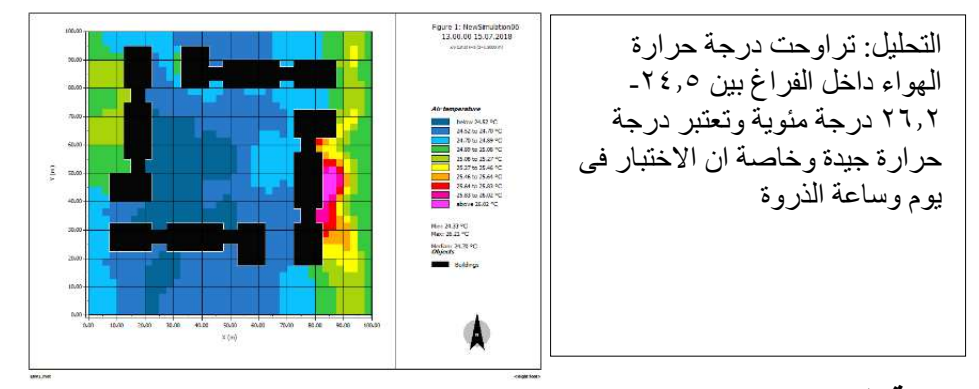

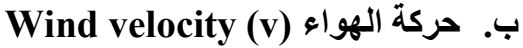
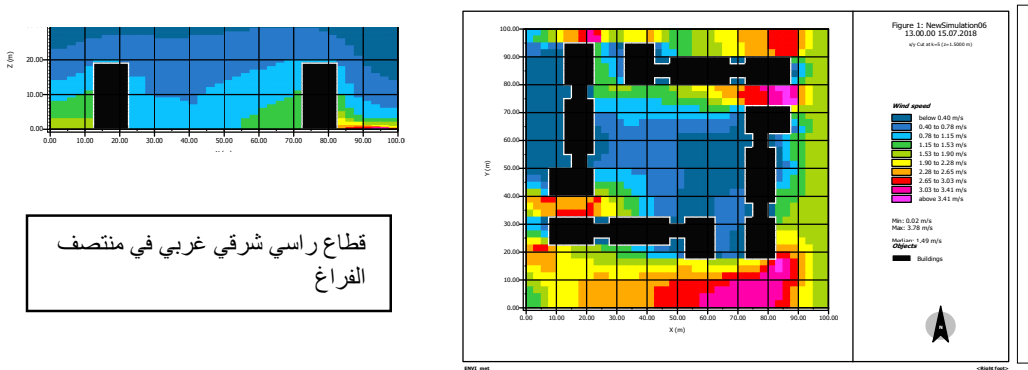

التحليل:

يوضح الثكل سر عة الهو اء داخل

الفر اغ حيث تقل سر عته داخل

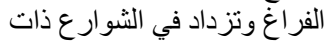
التوجيه الشرقي الغربي

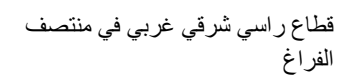


هـ؛ نتائج دراسة عناصر تصميم الفراغات العمرانية المؤثرة على الراحة الحرارية داخل مصفوفة القياس

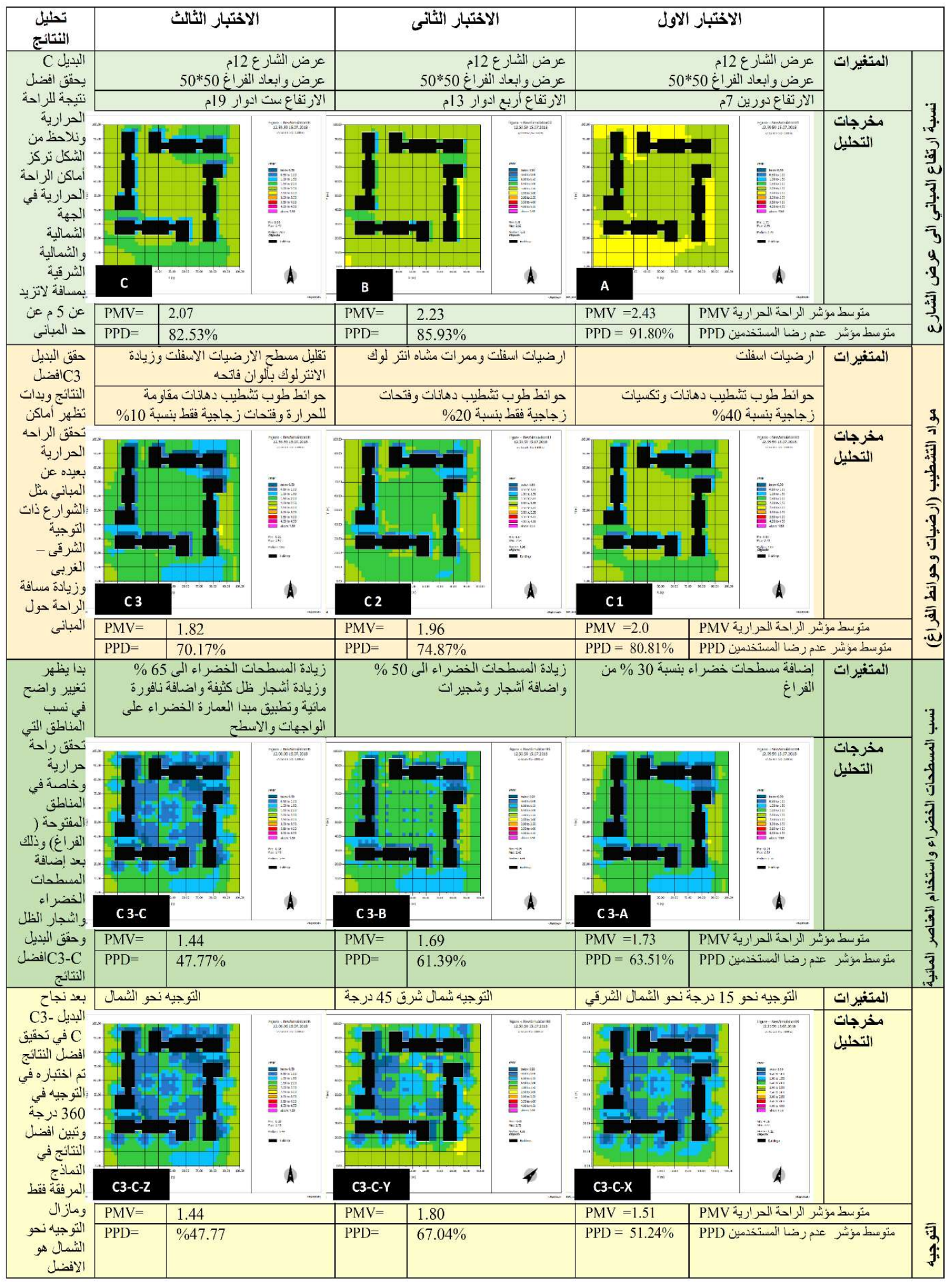




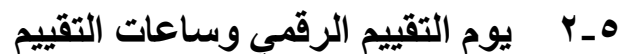

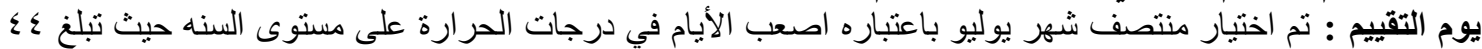

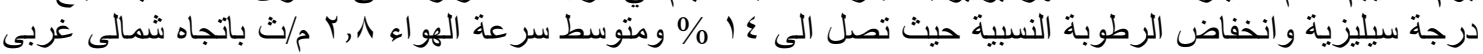

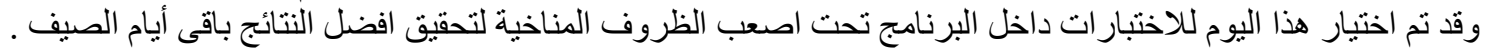

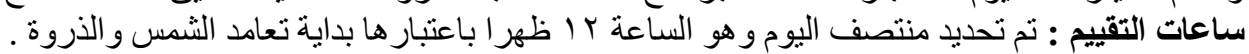

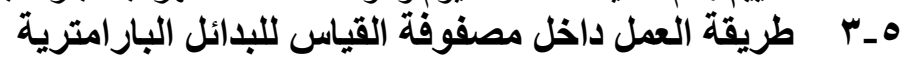

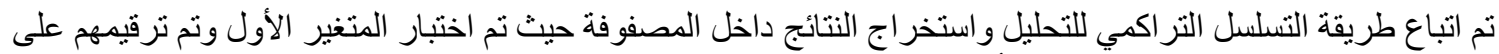

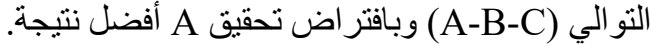

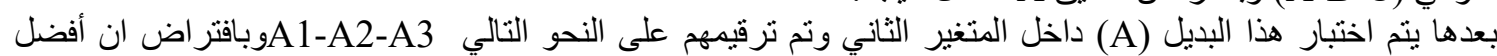

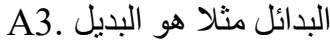
تأتى الخطوة التالية حيث ينم ادر اج هذا البديل ( A3-A3) داخل المصفوفة الافقية للتحليل بالمتغير الثالث وينم الاختبار داخل

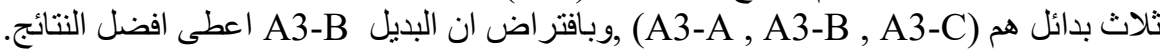

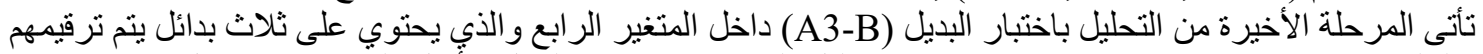

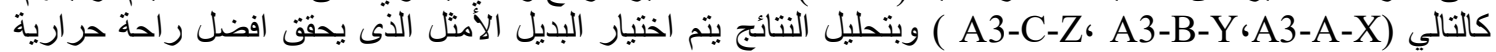
طبقا لُّخر جات البرنامج.

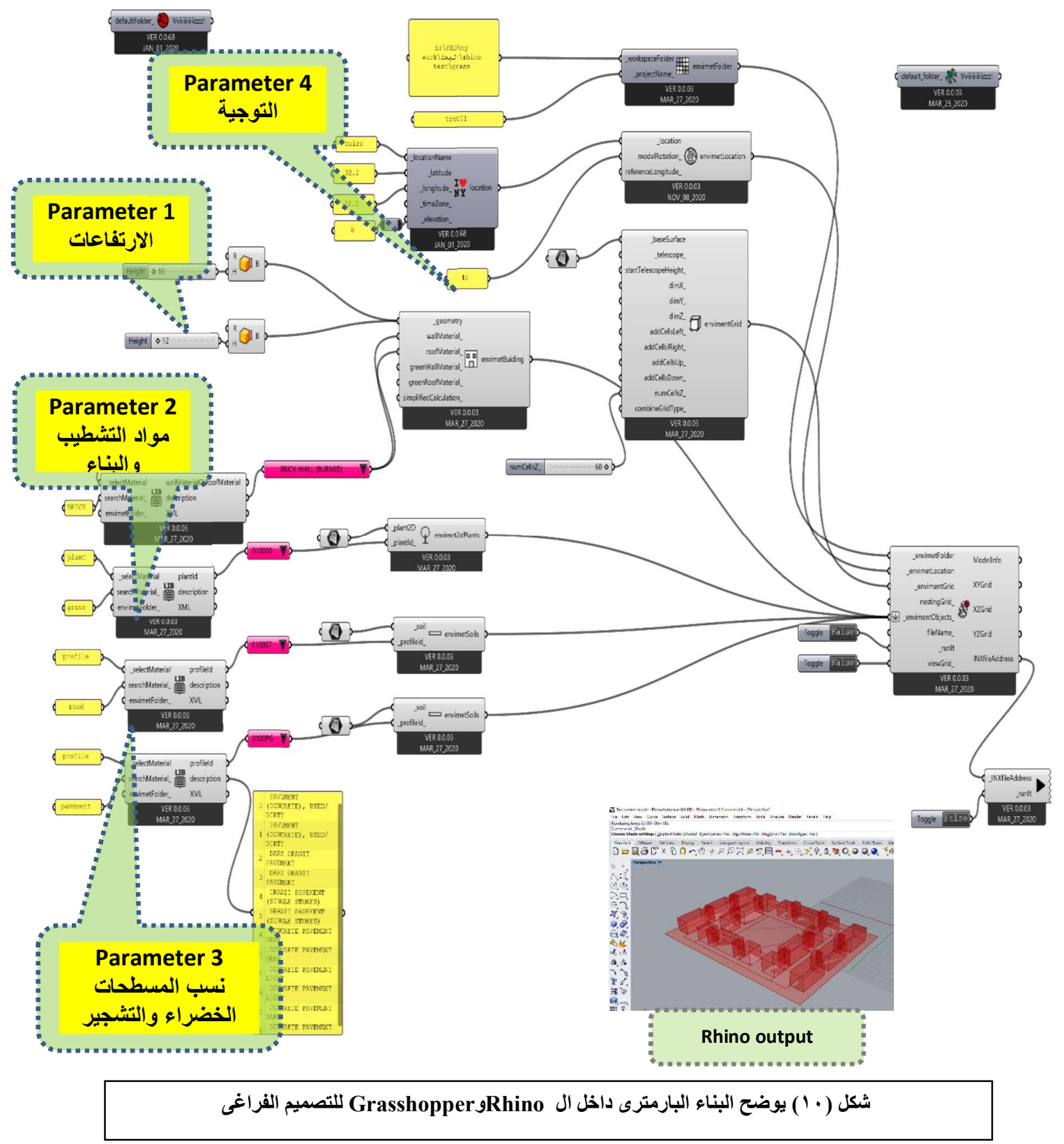


ت. ت نسب المسطحات الخضر اءء والعناصر المائية

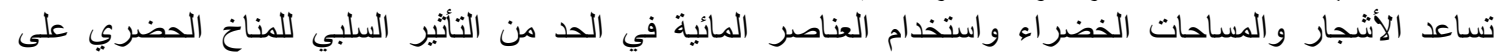

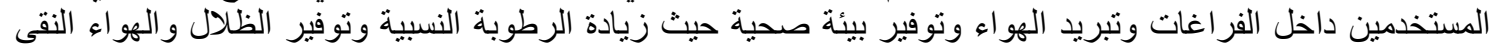

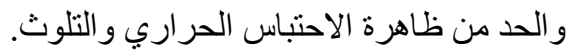

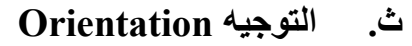
يعتبر التوجيه أحد اهم العو امل المؤثرة على التشكيل العمر اني البيئي وذلك لتحقيق الراحة الحر ارية من خلال در اسة توجيه

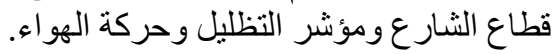
جدول (ץ) مصفوفة القياس داخل البرمجيات البارامترية المستخدمة

\begin{tabular}{|c|c|c|c|c|c|c|}
\hline 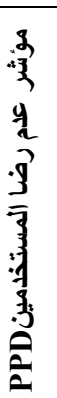 & 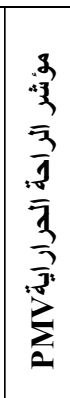 & 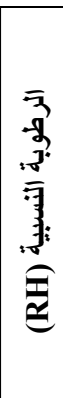 & 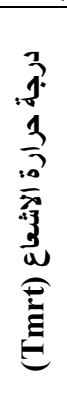 & 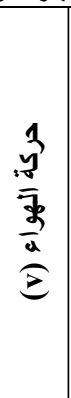 & $\begin{array}{l}\frac{3}{3} \\
\frac{1}{3} \\
\frac{1}{3} \\
\frac{3}{a} \\
\stackrel{5}{0}\end{array}$ & \\
\hline \multirow{4}{*}{\multicolumn{6}{|c|}{ و البدائل التصميمية مصممه على التحاة ب GRASSHOPPER }} & 1 ـ نسبة الارتفاع الى عرض الثارع والفراغ \\
\hline & & & & & & r ץ- مواد التشطيب (ارضياتَ وحوائط الفراغ) \\
\hline & & & & & & "َـ نسب المسطحات الخضر اء والعناصر المائية \\
\hline & & & & & & ـ ـ التوجيه \\
\hline \multicolumn{7}{|c|}{ النتائح والتحليل } \\
\hline
\end{tabular}

هـ اعداد النمذجة البار امترية للبدائل التصميمة (الار اسة التطبيقية)

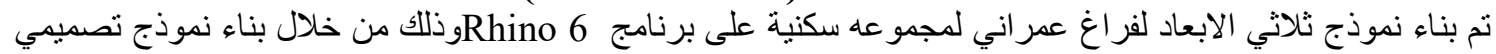

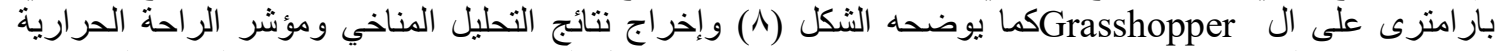

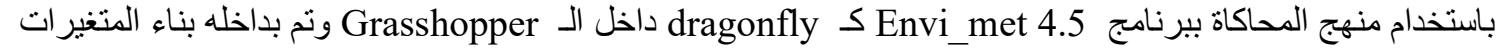
parameter

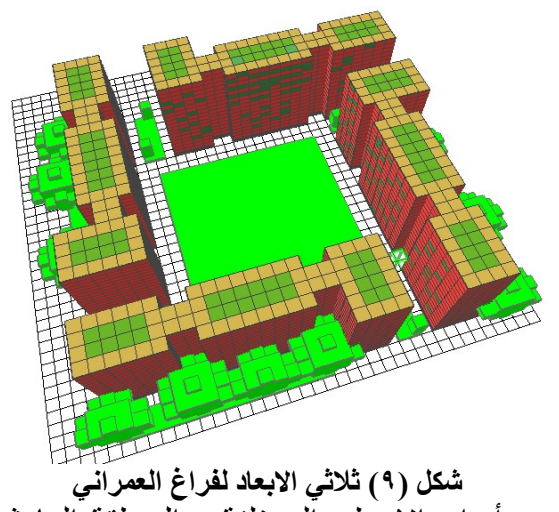

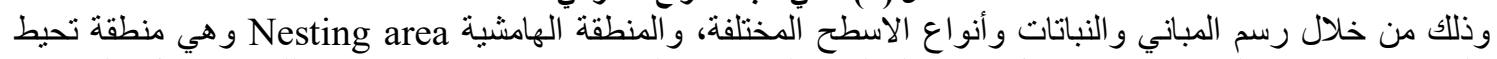
بالنموذج من جميع الجهات كإطار عمل لإتمام العمليات الديناميكية المناخية، كما تم تحديد نموذج للتربة يشتمل على مواد التها التشطيب.

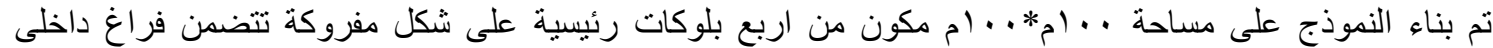

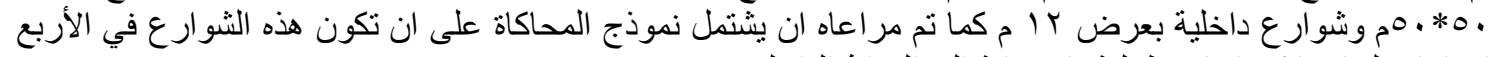

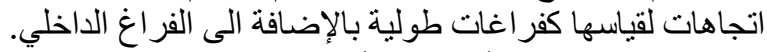

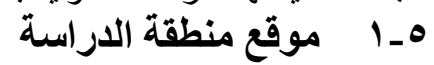
تم اختيار منطقة الدر اسة في نطاق مدينة نصر باعنة باعتبار ها منطقة صحر اوية كامتداد شرقى للقاهرة وتفتقر الى التصميمات التي تراعى النو احى البيئية 


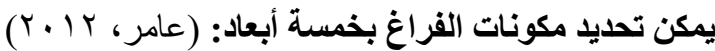 البعد الأول: المستوى الركأل أسبي (الحوائط)}

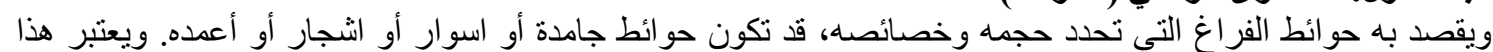

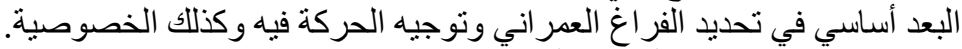

البعد الثاني: المستوى الأفقي (الأرضيات)

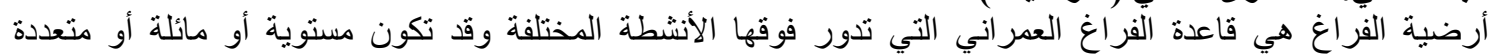
المستويات وقد تكون صلبة (بلاط) أو لينة (مسطح مائي) ويرتبط هذا البعد بالحو ائط حيث إنها هي التي تحدد شكله.

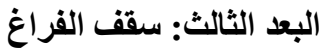

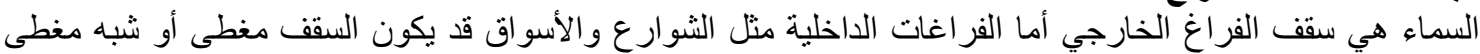

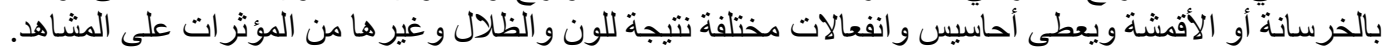

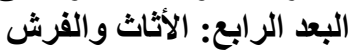
عادة ما يسمى هذا البعد بعناصر تنسيق الموفئ (land scape) ويكون لها دور وظيفي أو جمالي بالفر اغ وتعطى مقياس مناسب للفر اغ وهي تكمل الصورة الصناصن الذهنية. وتتمثل في أعمدة الإنارة و الأكثاك و المقاعد و المظلات و الأشجار و النباتات و العلامات المميزة و العناصر المائية و التماثيل

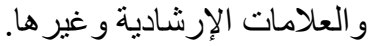

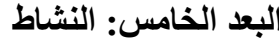
يتم تحديد نشاط الفراغ من العناصر الموجودة بداخله فالأنشطة الإنسانية في الفراغات العمرانية هي التي تحدد ملامح

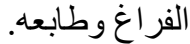
أنواع الفراغات الفراء الفر اغات العمر انية تنتشكل وتتكون بصور متعددة الأنو اع و الأشكال فمنها.

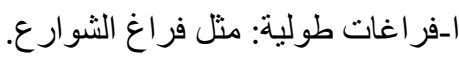

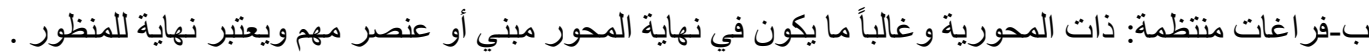
ج-فر اغ مسقوف: يعطي الإحساس بالحماية و الر احة.

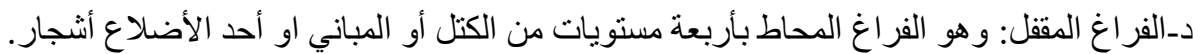

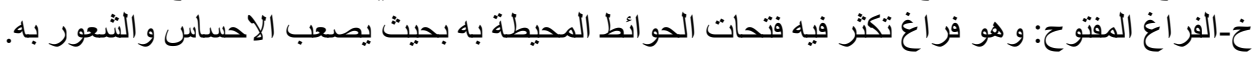

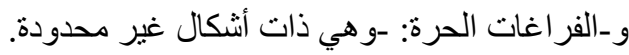

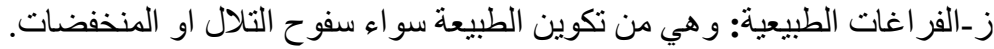

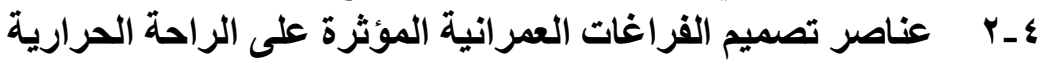

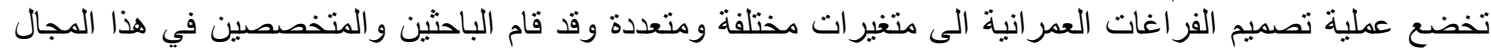

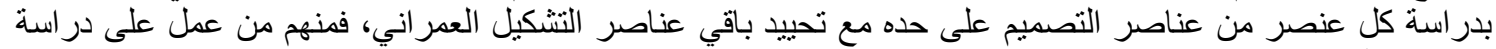

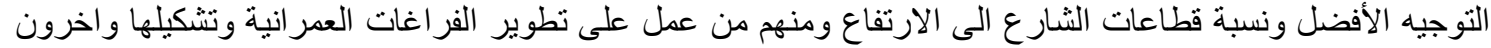

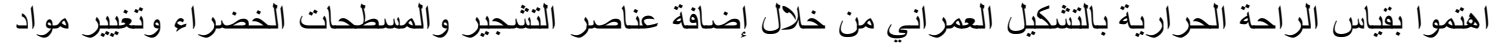

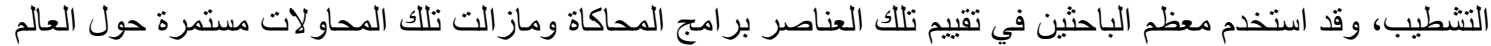

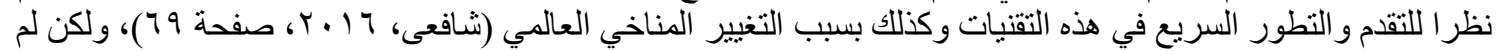

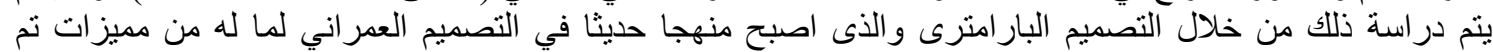

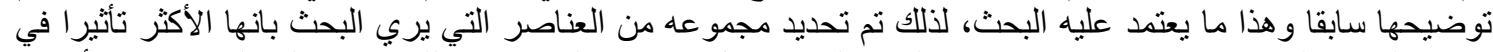

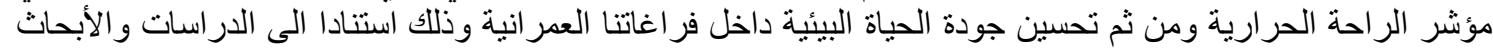

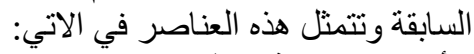

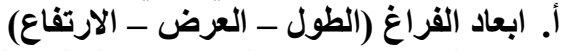

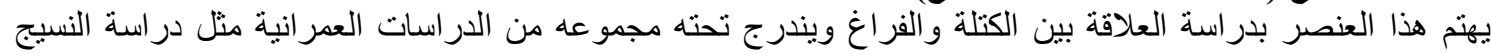

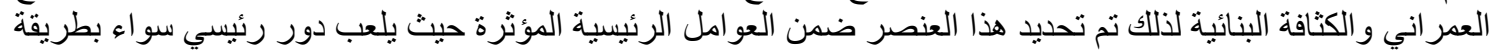
مبانشرة او غير مباشرة.

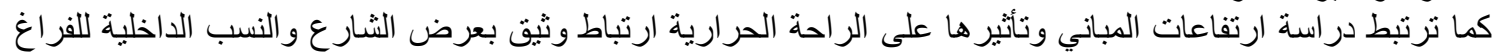

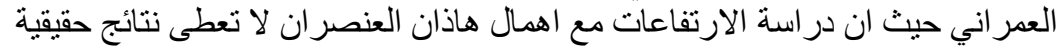

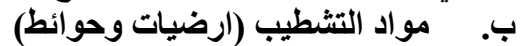

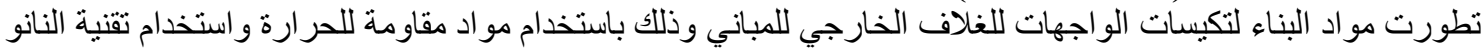

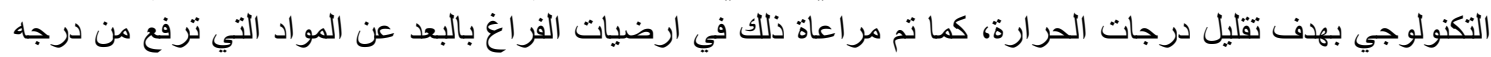

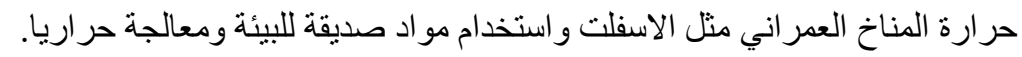




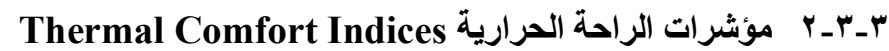

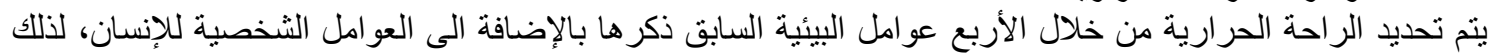

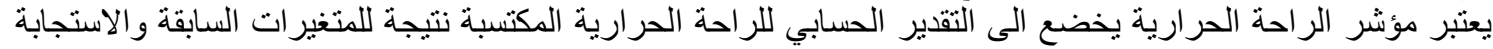
الحسية لجسم الانسان.

تعددت مقاييس مؤشر الراحة الحرارية وفقا لنوع و عدد المتغيرات التي تدخل في عملية القياس، لذلك تم تصنيفها الى

مجمو عتين رئيسيتين: (Toudert, 2005) أ. مؤشر رثين تجرين:

تعتمد على تقدير درجة حرارة الهربية الهو اء و الرطوبة النسبية وسر عة الرياح و لا تأخذ في اعتبار اتها وظائف الأعضاء الحيوية

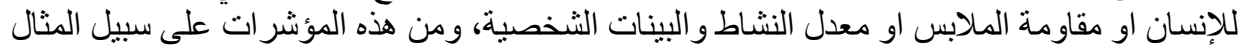

(ET-RT-HOP-WCI)

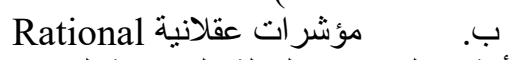

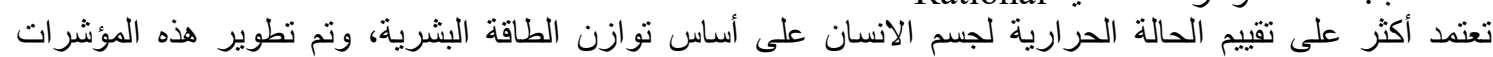

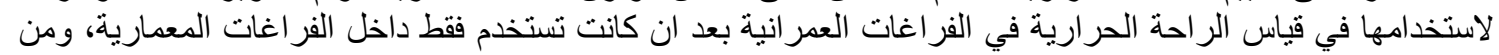
هذه المؤشرات على سبيل المثنال (ITS-HIS-PMV-PET).

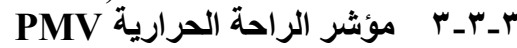

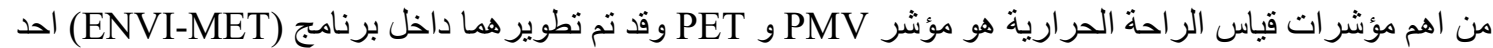

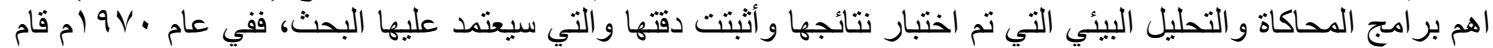

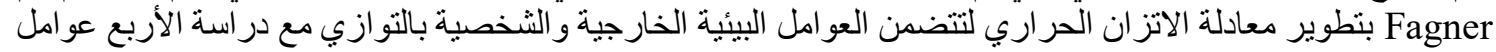

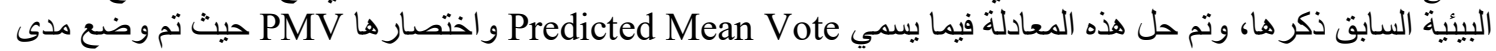

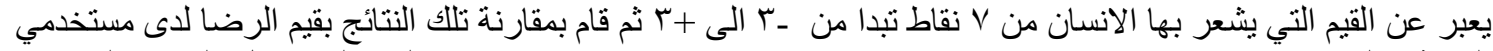

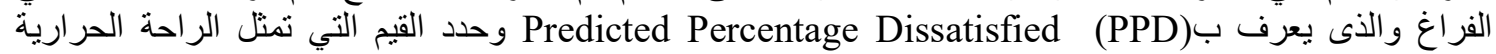

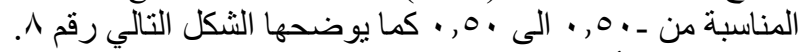

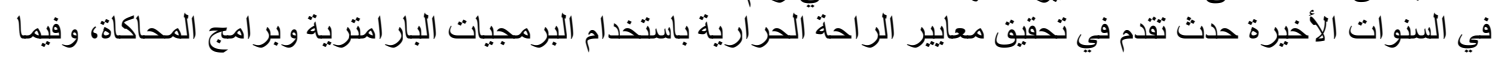

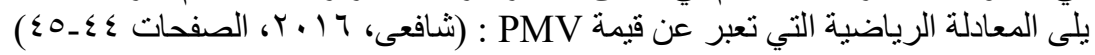
$\mathrm{PMV}=(0303 \mathrm{EXP})-0.036 \mathrm{M})+0.028) \mathrm{L} \quad \mathrm{EQ}(3.2)$

Thermal load(L)

(M) Metabolic rate الفرق بين انتاج الحرارة الداخلية وفقدان الحرارة في البيئة الفعلية لشخص افتر اضي في قيم الراحة

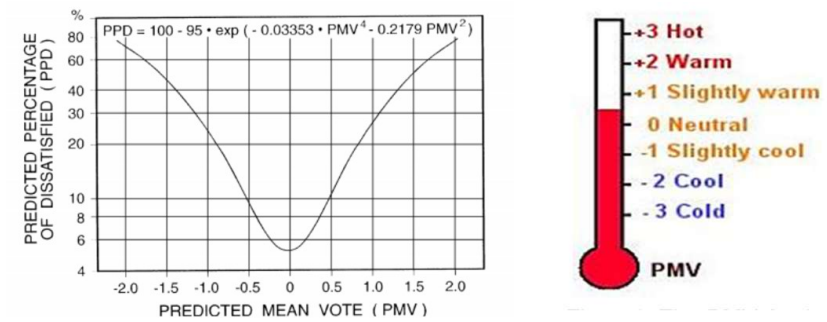

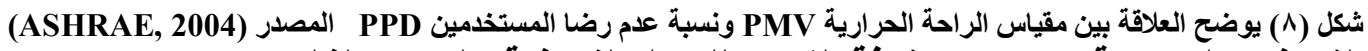

ـ ـ الفراغات العمرانية واعداد مصفوفة القياس للبدائل الفراغية التهنة (المحور الثالث)

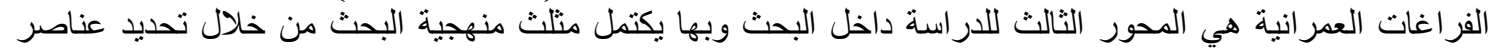

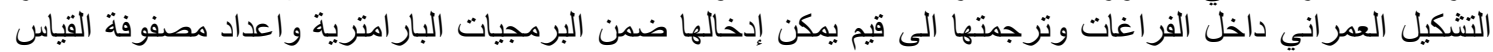

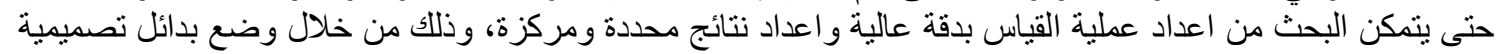

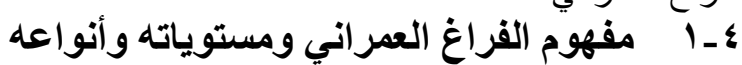

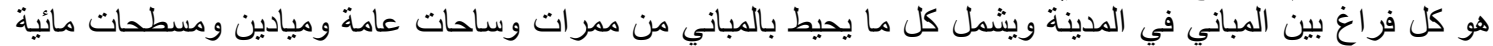

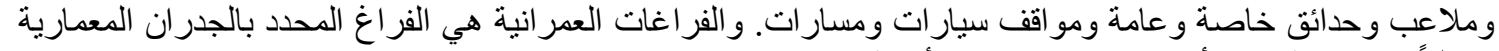

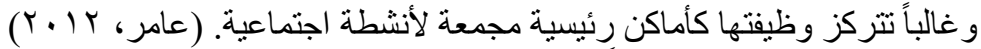

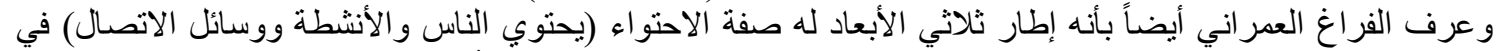

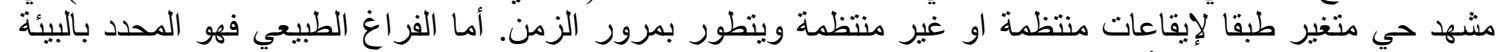

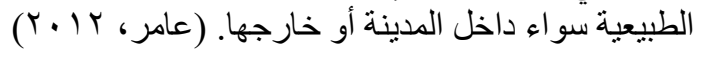


يوضح الجدول السابق مؤشرات جودة الحياة البيئية طبقا للأبعاد الفرعية كما يوضح نوع وطريقة قياس المؤشر وسيقوم

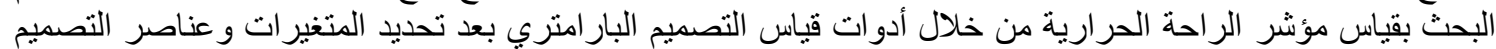

ب-r الزراحة الحرارية كمؤشر لقياس جودة الحياة البيئية

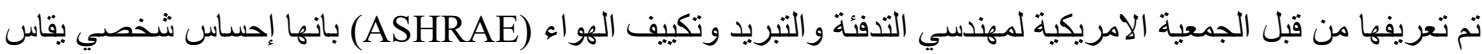
بمدي رضا مستخدمي الفراغ حيث انها حالة تعبر عن ارتياح الانسان بالبيئة الحر ارية وينم تقييمها من خلال المستخدمين.

(ASHRAE, 2004)

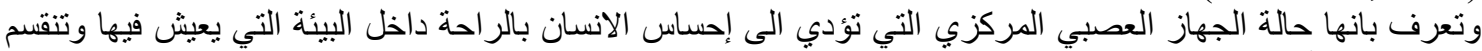

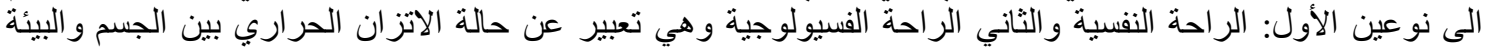

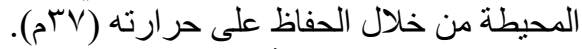

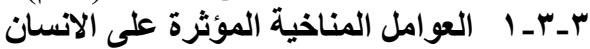

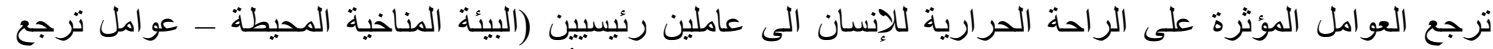

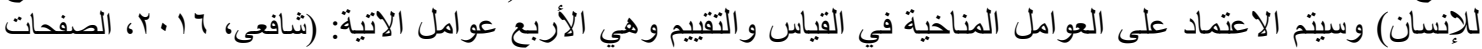

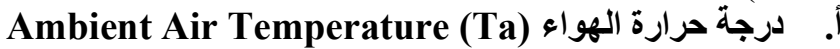

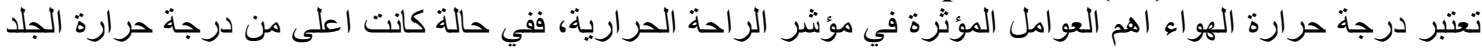

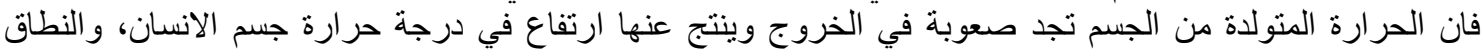

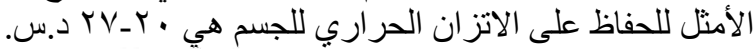

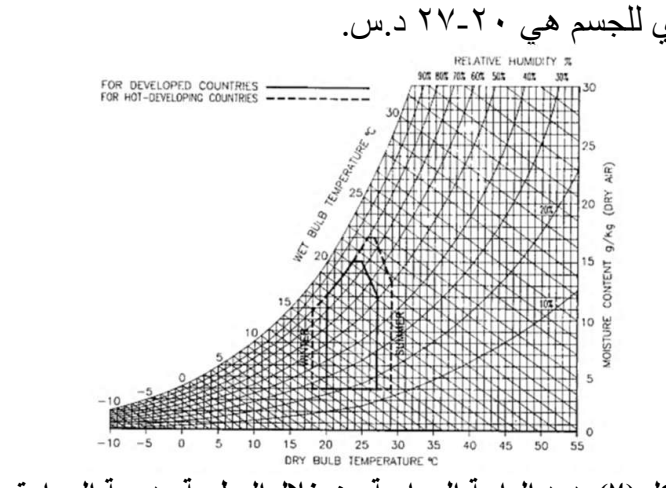

شكل (V)حدود الراحة الحرارية من خلال الرطوبة ودرجة الحرارة

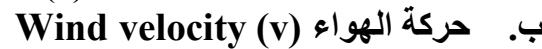

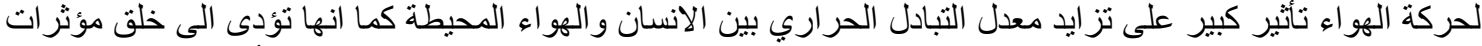

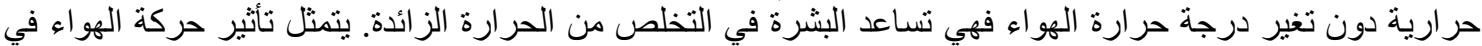

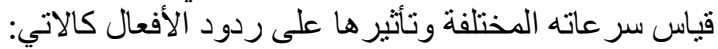

$$
\begin{aligned}
& \text { - } \\
& \text { - } \\
& \text { - } \\
& \text { - } \\
& \text { - }
\end{aligned}
$$

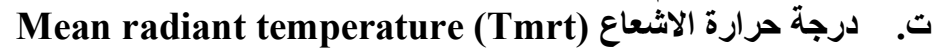

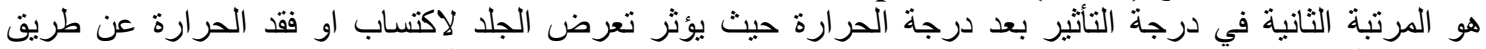

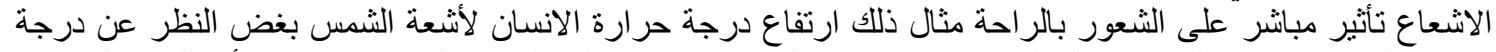

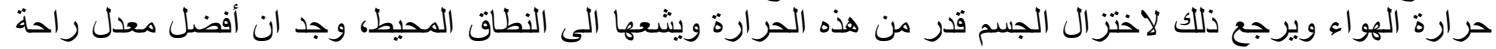

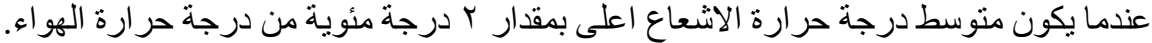

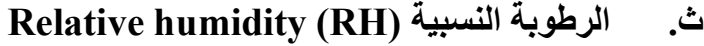

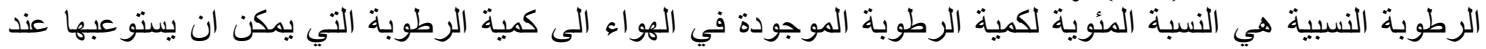

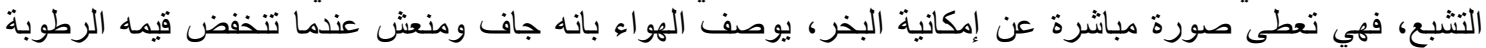

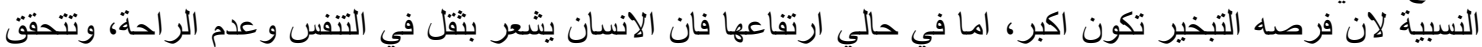

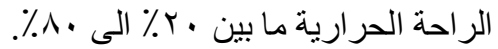


المؤشرات الذاتية هي مؤشرات تستخدم لقياس درجة رضات التهاء السكان عن الخدمات المتو اجدة بالمدينة كما تعبر عن مدي كفاءة هذه الخداء الخدات.

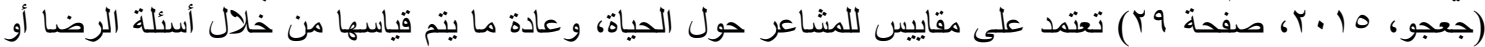

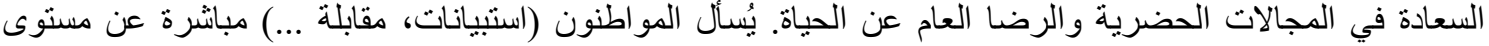

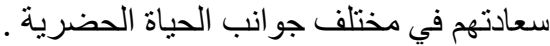

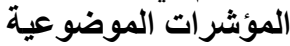

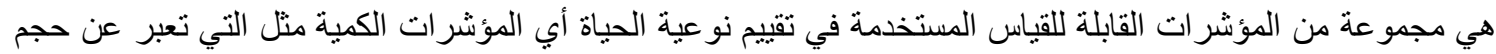

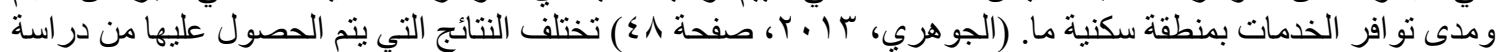

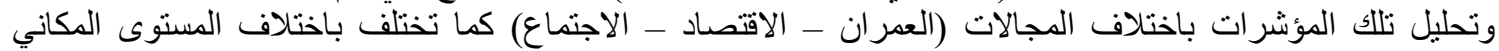

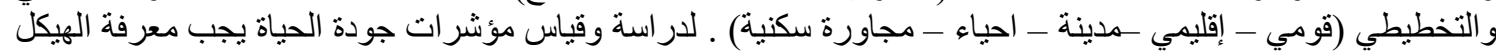

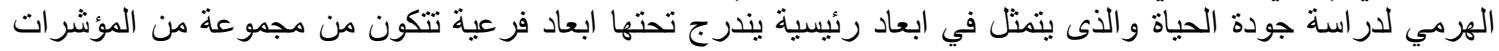

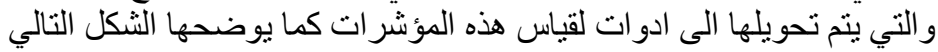

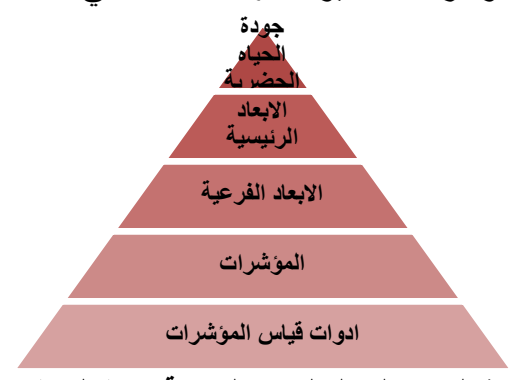

شكل (7) الهيكل الهرمي لاراسة جودة الحياة

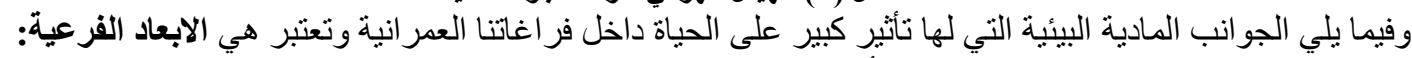

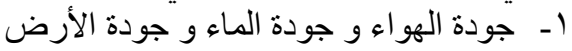

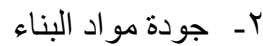
ك- جودة البيئة المحلية

ع- - استخدام الطاقة

جدول (1) مؤشرات جودة الحياة البيئية 0ـ إدارة النفايات و إعادة التدوير

\begin{tabular}{|c|c|c|c|c|c|c|}
\hline \multicolumn{2}{|c|}{ نوع المؤشر } & \multicolumn{2}{|c|}{ القياس } & \multirow[t]{2}{*}{ المؤشرات } & \multirow[t]{2}{*}{ الابعاد الفزعية } & \multirow[t]{2}{*}{ الرئيسي } \\
\hline \& 3 & $\frac{7}{2}$ & कु & y & & & \\
\hline * & & & * & عدد محطات مر اقبة جو دة الهو اء ونسبة تغطيتها & \multirow{5}{*}{ مؤشرات جودة } & \multirow{18}{*}{$\begin{array}{l}\overline{7} \\
\overline{7} \\
\bar{y}\end{array}$} \\
\hline * & & & * & مدي مطابقة جودة الهو اء للمو اصفات القياسية. & & \\
\hline * & & & * & نسبة المصانع التي تفي بمقاييس انبعاث الملوثات (بالمدن الصناعية) & & \\
\hline$*$ & & & $*$ & عدد الحالات المرضية المرتبطة بتلوث الهواء & & \\
\hline$*$ & $*$ & $*$ & * & تحديد مصادر ومستويات الضوضناء & & \\
\hline$*$ & & & * & معدلات تلوث مياه الثرب. & \multirow{5}{*}{ مؤشرات جودة } & \\
\hline$*$ & & & * & مقارنة كميات المياه المستهلكة بالمتاحة. & & \\
\hline$*$ & & & * & تلوث المسطحات المائية سواء الطبيعية او الصناعية داخل العمر ان. & & \\
\hline \multirow[t]{3}{*}{$*$} & $*$ & * & * & أنظمة تصريف مياه الامطار داخل الفر اغات العمر انية بالمدينة & & \\
\hline & & & & و الاستفادة منها. & & \\
\hline & $*$ & * & & مدى الاستمتاع بالبيئة الطبيعية و المناطق الخضر اء. & \multirow{4}{*}{ مؤشرات جودة البيئة المحلية } & \\
\hline$*$ & & & * & مؤشر الر احة الحرارية الخارجية & & \\
\hline * & & & * & مؤشر الر احة الصوتية للبيئة الخارجية & & \\
\hline * & & & * & مؤشر الراحة الضوئية للبيئة الخارجية & & \\
\hline$*$ & & & * & عدد المشرو عات التي تعتمد على الطاقة المتجددة. & \multirow{2}{*}{ مؤشرات جودة } & \\
\hline \multirow[t]{3}{*}{$*$} & $*$ & $*$ & * & كفاءة ونسبة استخدام الطاقة المتجددة بالمدينة & & \\
\hline & $*$ & $*$ & & كفاءة منظومة اداره المخلفات الصلبة و السائلة. & \multirow{2}{*}{ مؤشرات إدارة } & \\
\hline & $*$ & * & & استخدام تقنيات إعادة التدوير & & \\
\hline
\end{tabular}




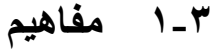

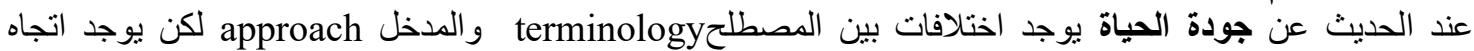
لاستخدام هيكل أفكار conceptual framework لوصف جودة جئ دوة الحياة وهو مبنى على فكرة وجود خريطة من المؤشرات

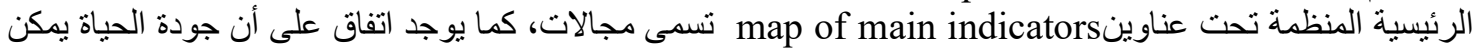

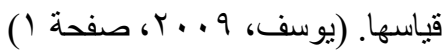

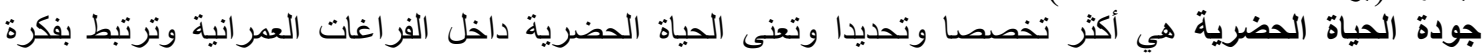

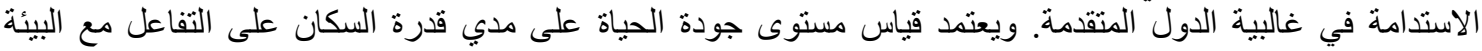

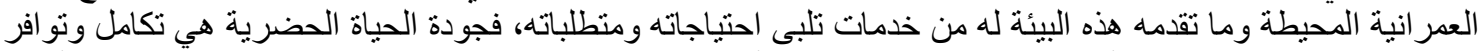

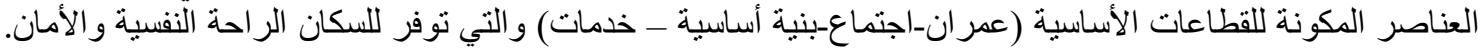

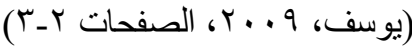

جودة الحياة الحضرية تثير الى التصميم العمر اني الذي يقوم على تحقيق تتمية منو اصلة ومستدامة مع تحقيق جودة حياه

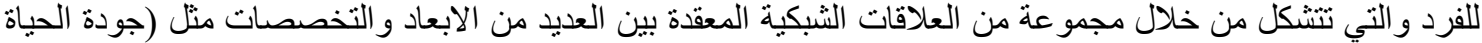

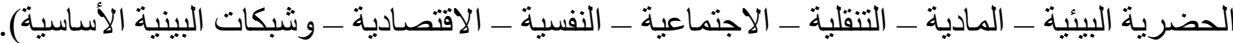

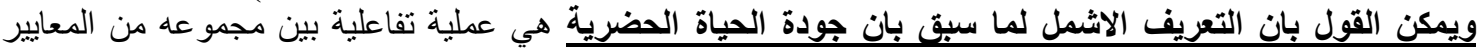

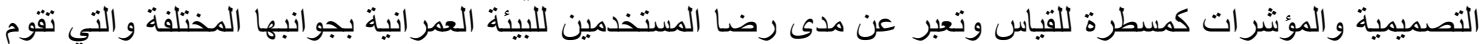

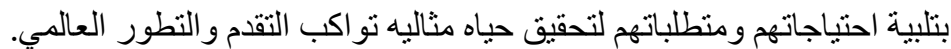
جودة الحياة الحضرية البيئية

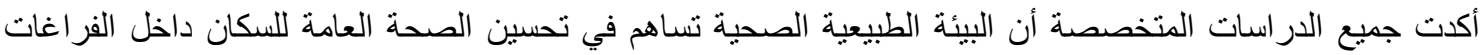

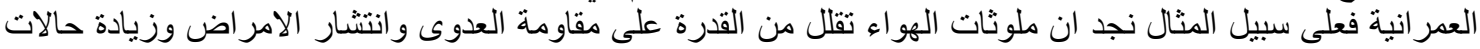

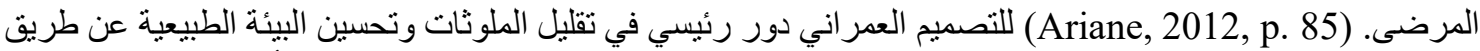

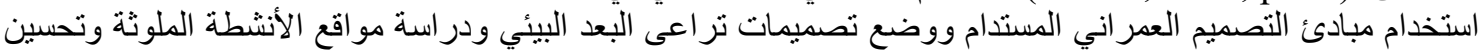

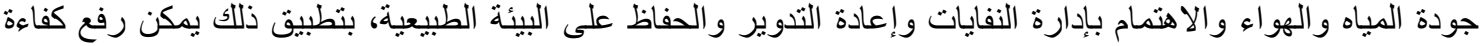

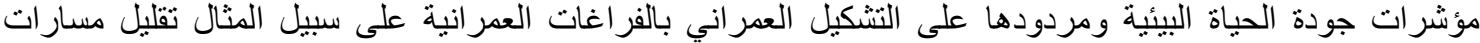

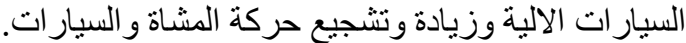

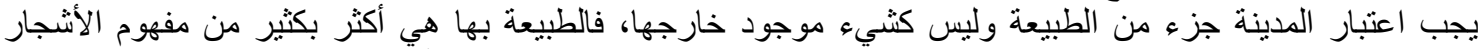

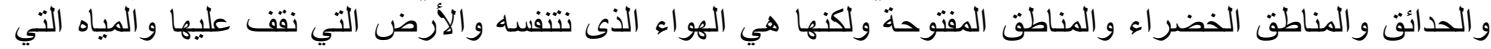

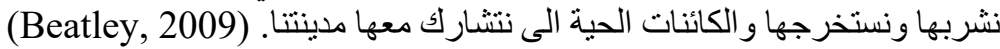

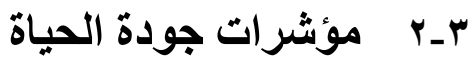

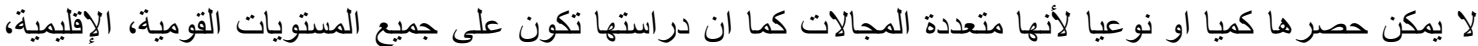

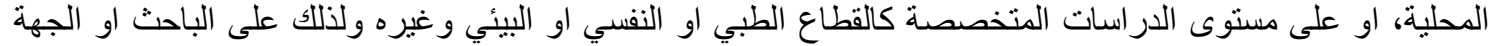
البحثية ان تختار ما هو مناسب لنو عيه الدر اسة وتحديده بدقها ويتوقف ذلك الك على مجمو عهد من العو امل:

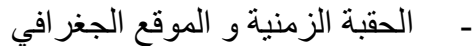

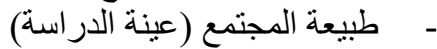

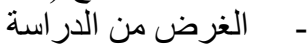

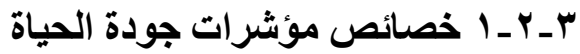

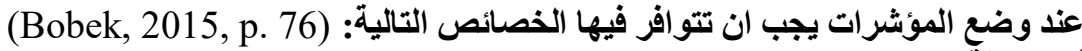

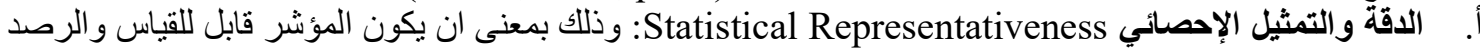

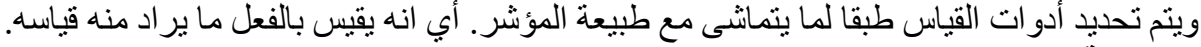
ب. الصلاحية Validity (مع إمكانية التحقق ومر اقبة جودة البيانات) ت. الموضوعية Objectivity: وهي ان تتسم بالوضوح وسهوله الفهم وتعطي تقريبا تفس النتائج في حالة در استها من باحث اخر في بيئة مماتلكة.

ث. إمكانية المقارنة والتوحيد القياسي Standardization / Comparability وذلك على المستوى الطولي (عامل

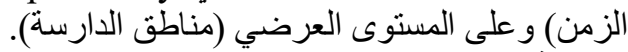

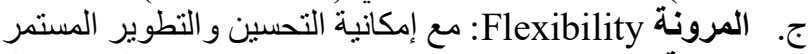

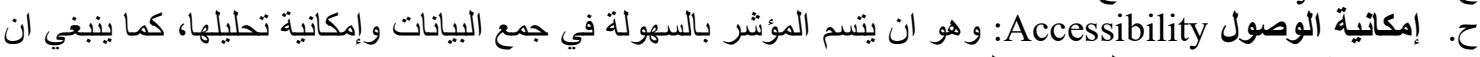
يعكس شيئا جو هريا عن المجالات التي يتم در اساتها.

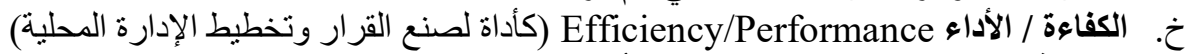

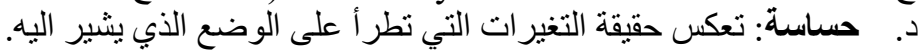

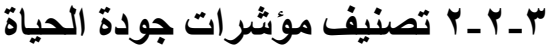


تمر عملية التصميم بمجموعة من المر احل التي يجب ان براعى فيها الدقة والثفافية سواء في ادخال البيانات او الاستتاد

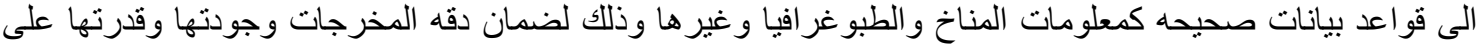

حل المشكلات و الابتكار ويوضح الثكل التالي المر احل التي تمر بها عمليه التصميم البار امترى وهي ه مران مر احل رئيسية:
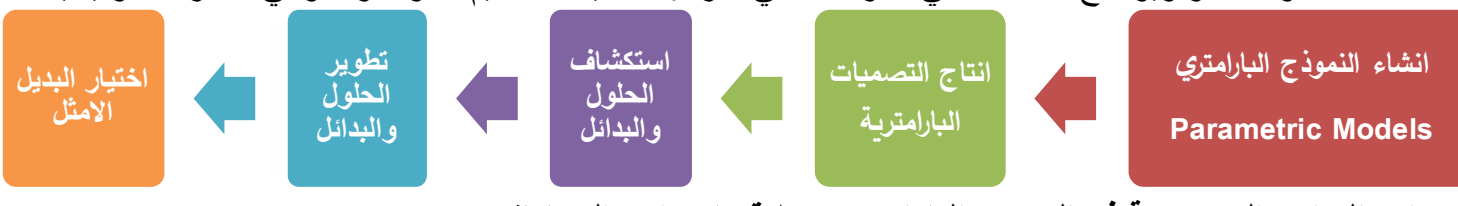

r ـ ـ اهم البرامج المستخدمة في التصميم البارامتري وعلاقتها ببرامج المحاكاة

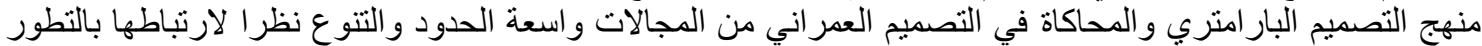

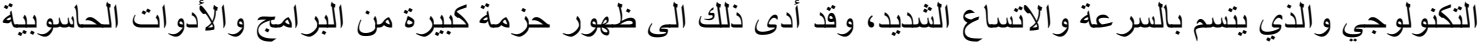

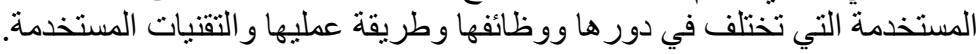

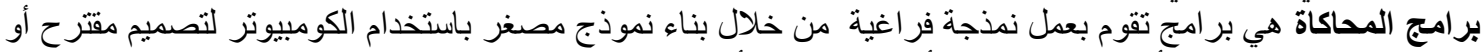

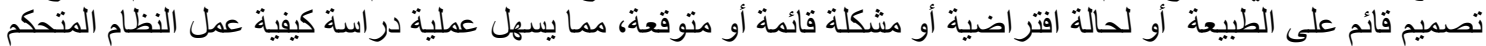

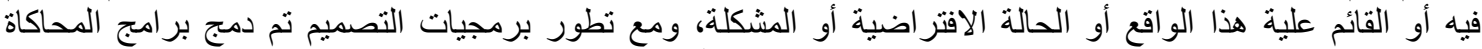

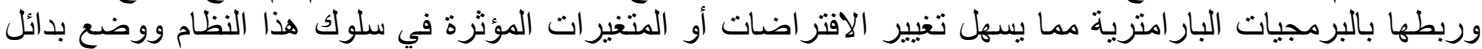

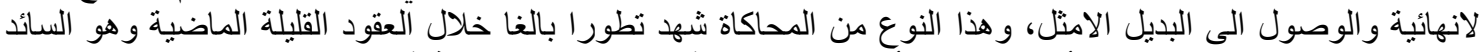

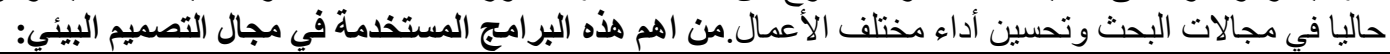

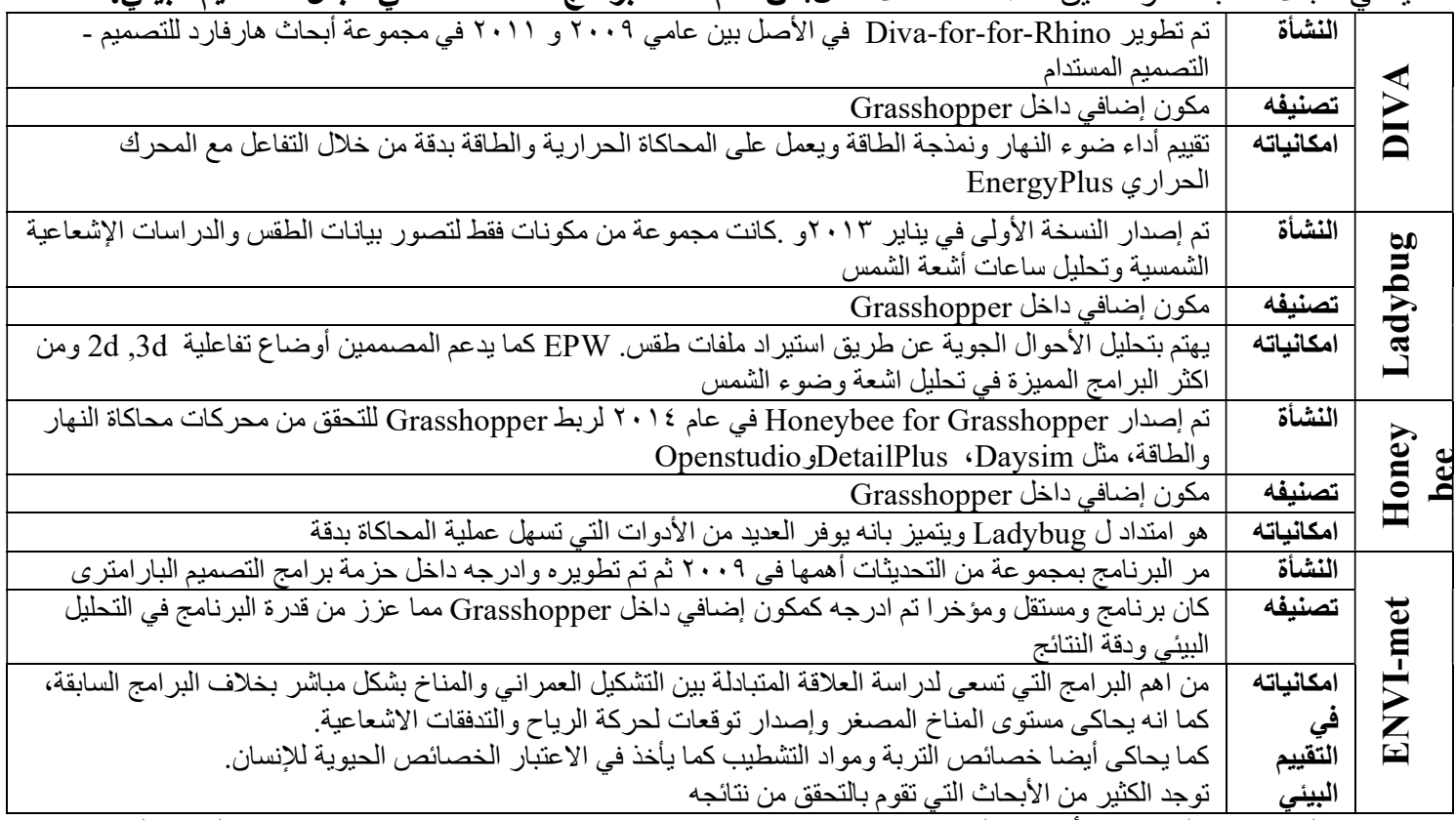

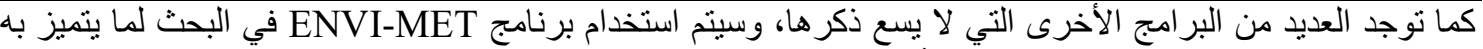

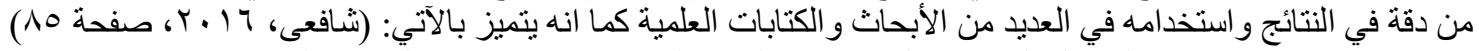

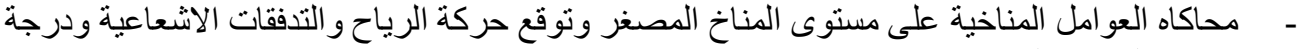

$$
\text { حر ارة الهواء و الرطوبة التفاخة. }
$$

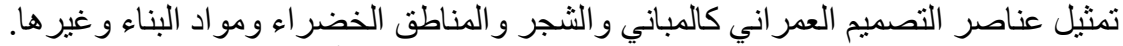

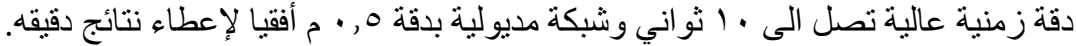
تم دمج الكثير من هذه البرامج كبرامج مساعدة

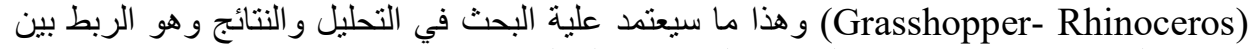

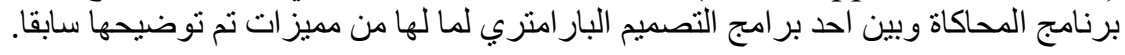


يو فر التصميم البار امتري إمكانية توليد العديد من البدائل التصميمة التي يمكن ان تتنج الأمثل واختبار ها واختيار ها بشكل

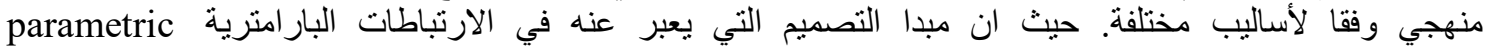

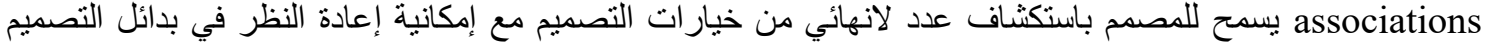

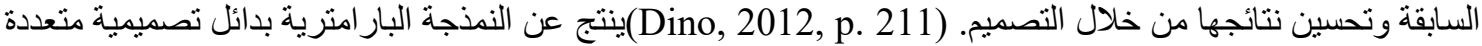
يتحقق كل منها بتعديل احد بارامترات النموذج او عدد منها. فالنموذج الواحد يمكن ان ينتج العديد من البدائل.

(Woodbury, 2017, p. 41) ت. مرونة التعديل والقدرة على التكييف

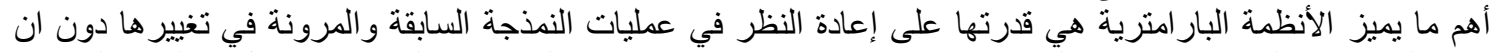

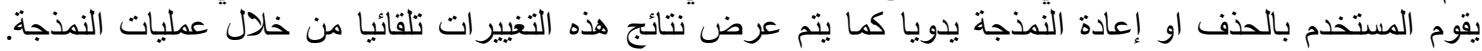
ويتميز بالمرونة لقدرته على انجاز التغييرات السريعة في الأفكار التصميمة في أي مرحلة من

ثر احل عملية التصميم.

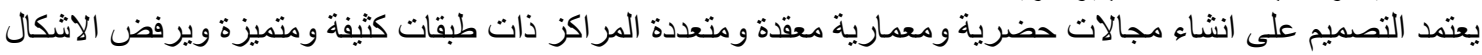

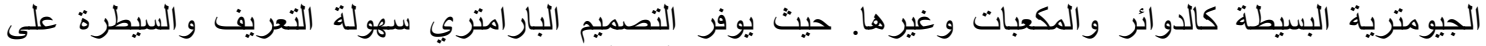

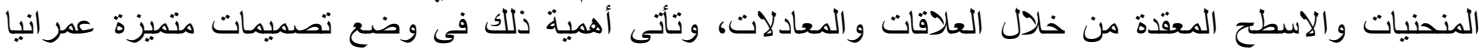

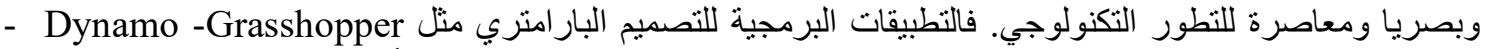
مaya -Rhino - Generative Components

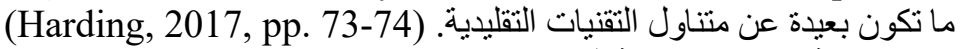

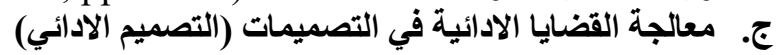

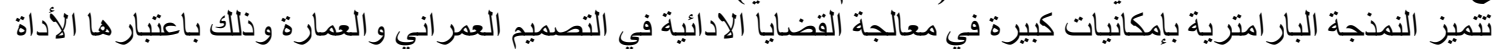

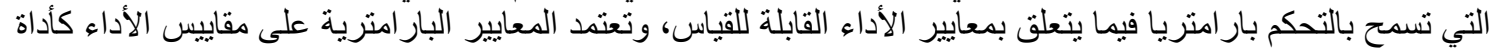
إرشّادية لوضع حلول وبدائل تصميمية تقوم على مؤشرات الأداء. (Dino, 2012, p. 213) (انشائيا - بيئيا مثل الأل أداء

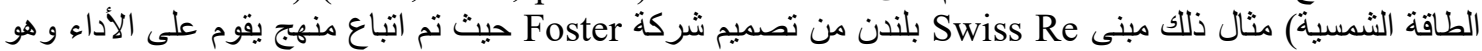

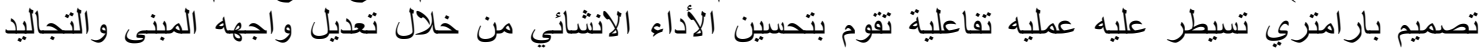

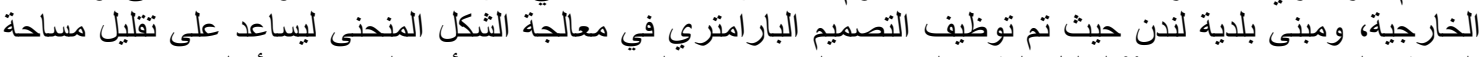

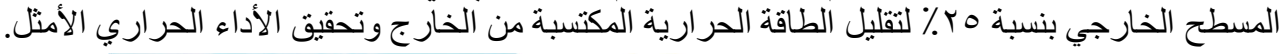
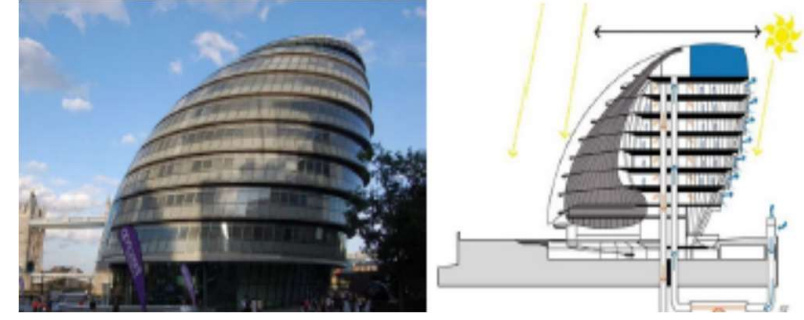

شكل(•) يوضح دور المنهج البارامتري في التصميم الادائي (مبنى بلاية لندن)

ح. إمكانية المشاركة بين تخصصات متعددة في العملية التصميمية التصنية

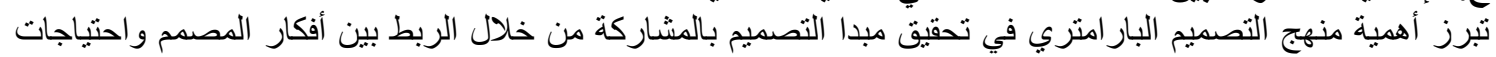

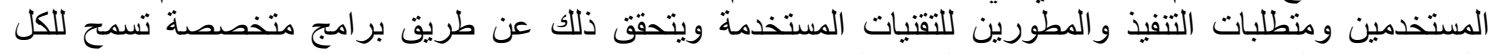

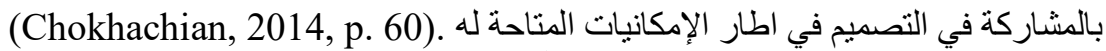

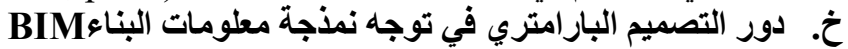

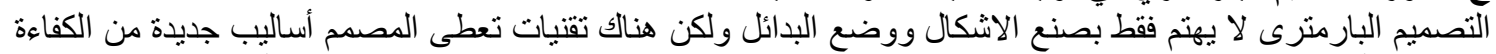

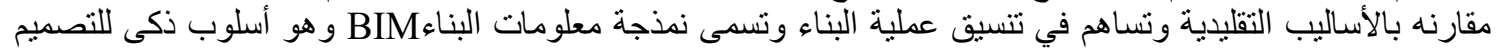

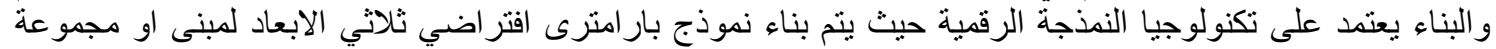

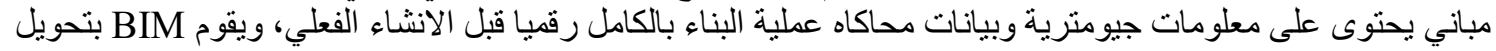

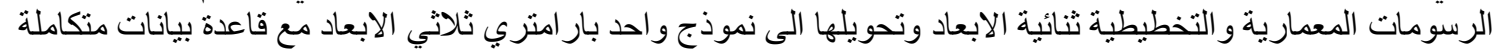

تحتوى على جميع معلومات البناء المرتبطة التبطة بالمشروع.

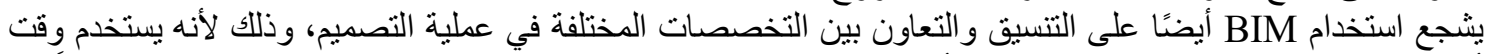

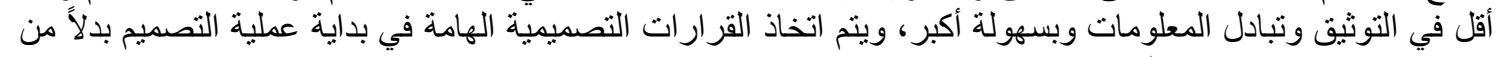

اتخاذها مؤخر المما يسبب تكلفة إضافية. (Feist, 2016, pp. 18-20) 
الحضرية الضخمة وفى الو اقع كلما زاد حجم المشروع كلما اكتشفت قدرة المفاهيم البار امترية على استيعاب وتتسيق هذه

التعقيدات الضخمة. (Schumacher, 2009, p. 15)

Conceptual Definition of Parametricism الفكرة التي تقوم عليها البار امترية

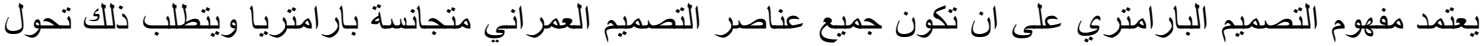

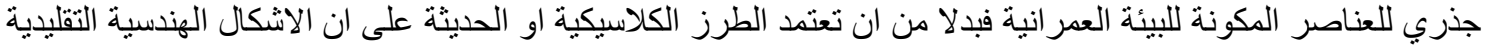

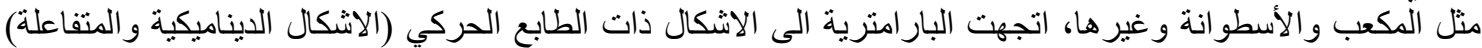

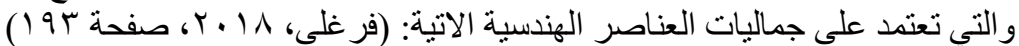
هurbs - - هي احد أنواع المنحنيات الثريطية عالية الجودة في بناء المجسمات وتعطي مجسمات ذات ذات اسطح ناعمة و عالية الجودة كثيرة المنحنيات.

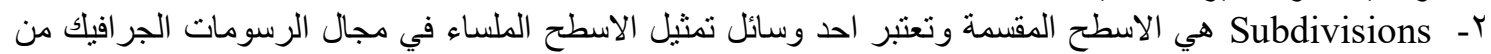

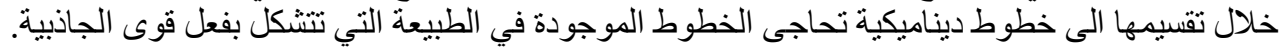

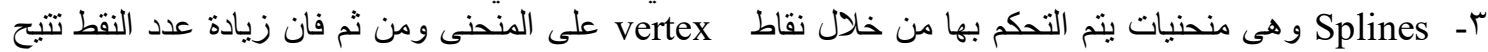

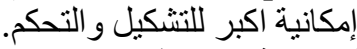

النشأة وبداية دمجه في التصميم العمر اني التي

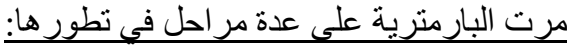

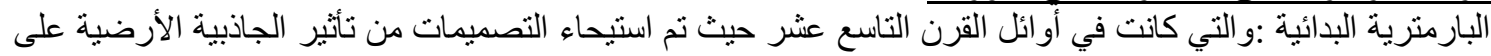

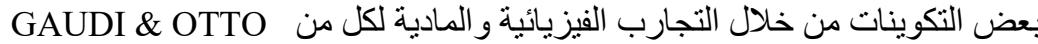

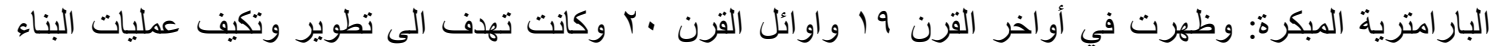

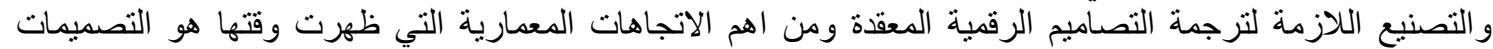

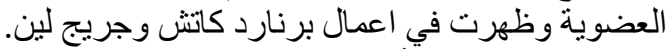

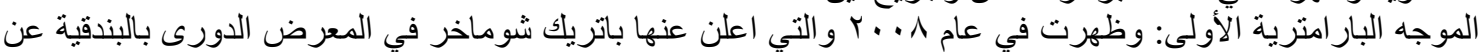

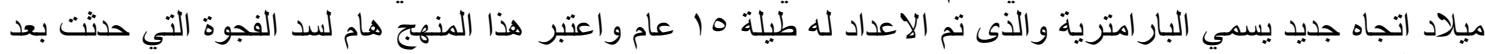
ازمة الحداثة وما بعدهاً.

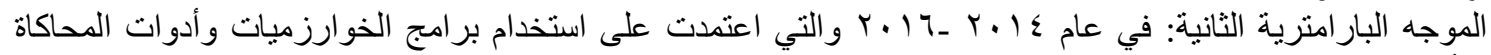

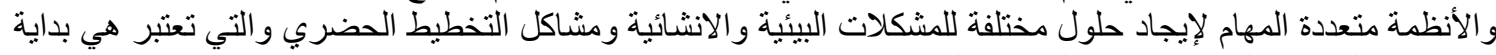
دمج اتجاه التصميم البار امتري في الإيجاد التصميم العمر انئي.

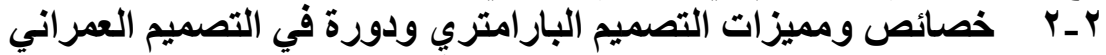

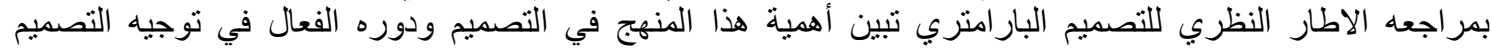

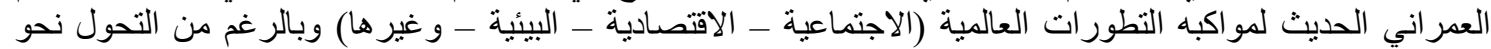

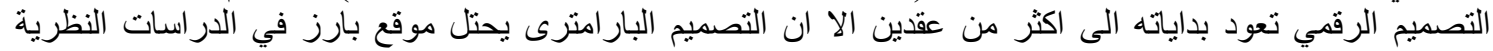
و العلمية على المنصيات العلمية العالمية.

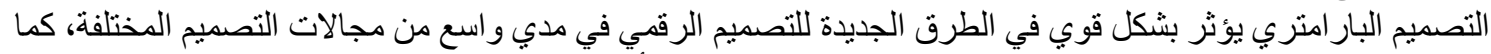

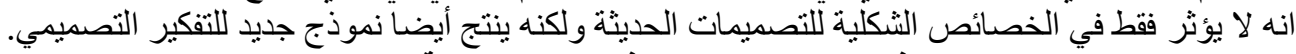
ويمكن تلخيص مبيز اتهـ ودورة في التصميم العمر انيى في المحاور الآتية: الحضري لمدينة البندئة

التوجه البار امتري parametricism بسمح للمصممين بتحقيق التتاغم الكامل في جميع مر احل ومستويات التصميم بداية

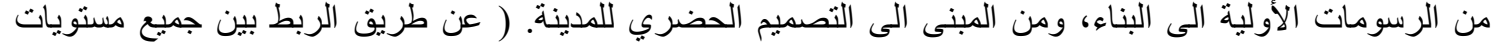

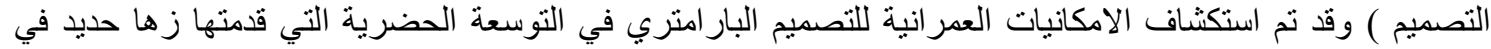

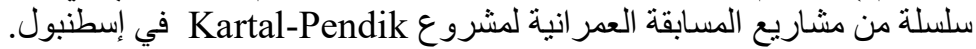

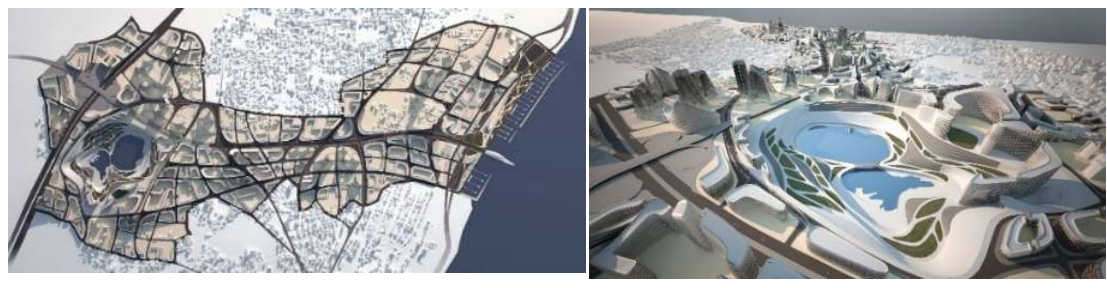

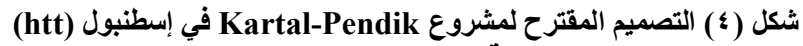

ب. انتاج واخراج عدد لانهائي من البذائل التصميمية الثمئروع 


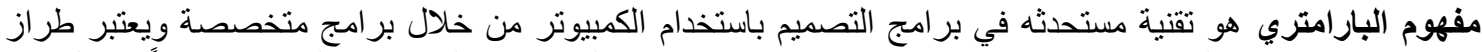

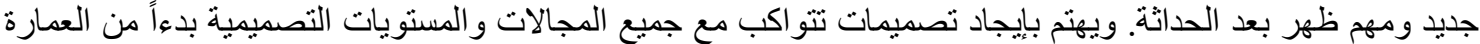

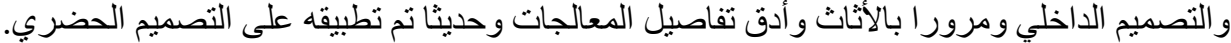
تعريف التصميم البارامتري

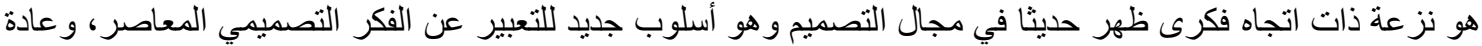

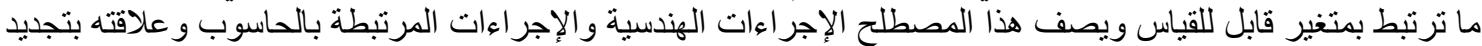

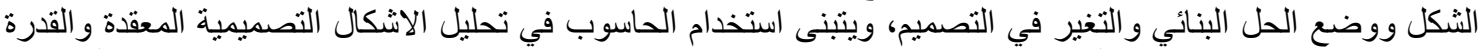

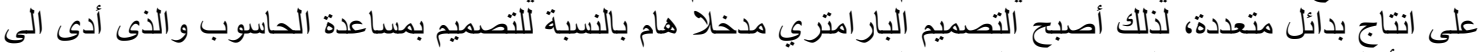

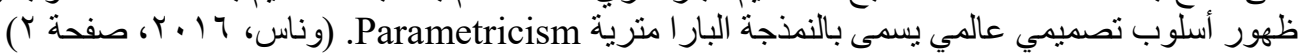

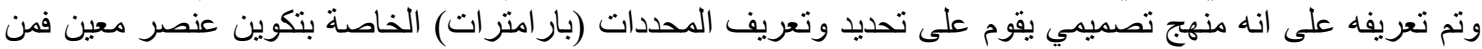

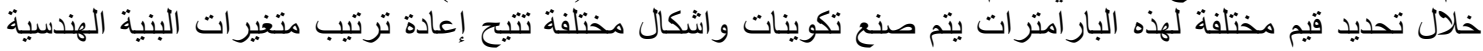

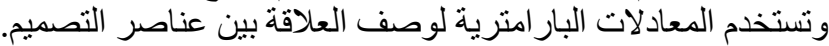

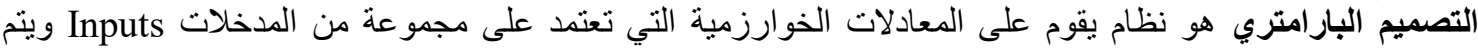

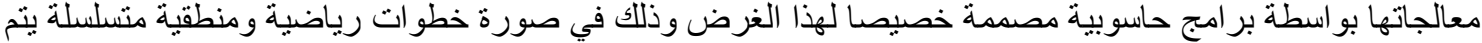
محاكاتها وترجمتها بصريا وصو لا لإنى الى البدائل التصميمية. (Jabi, 2013)

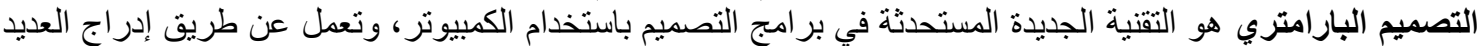

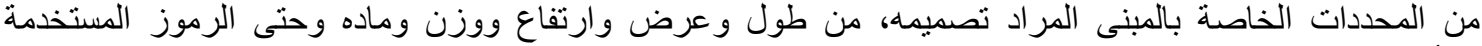

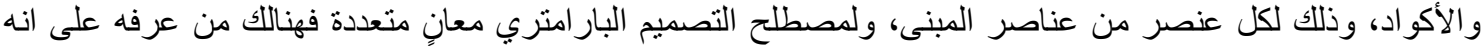

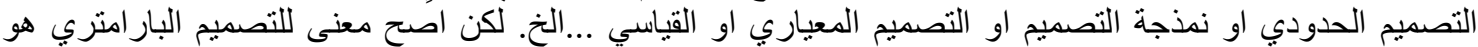

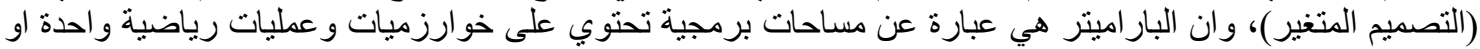

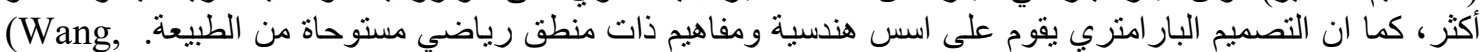

2010, pp. 236-239) مراحل عملية تكوين الثكل (التصميم) بارامتريا:

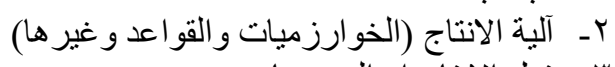

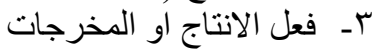

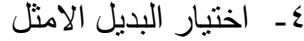

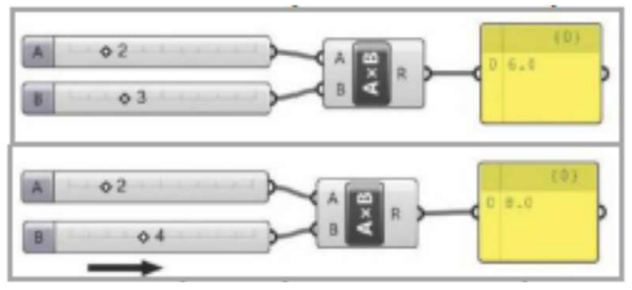

شكل ("آ) يوضح حد المعادلات البارامترية

Parametric-Algorithmic الفرق بين

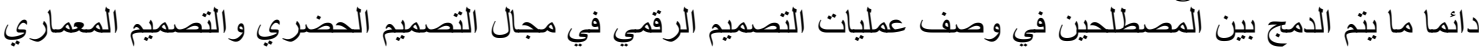

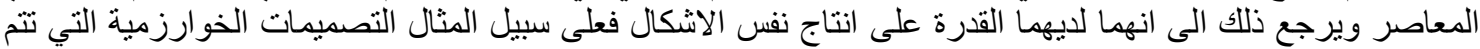

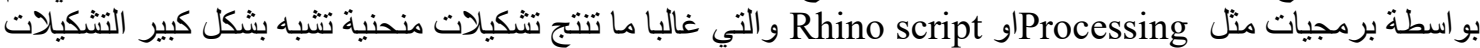

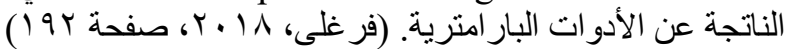

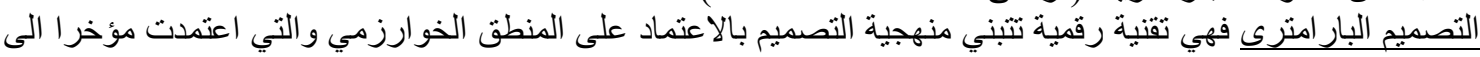

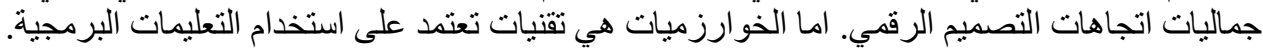

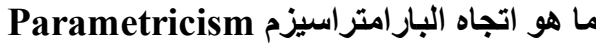

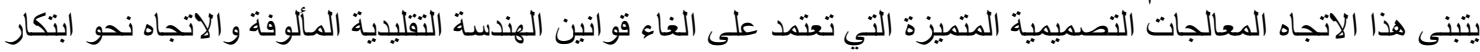

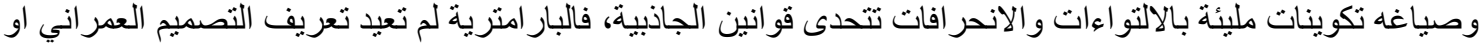

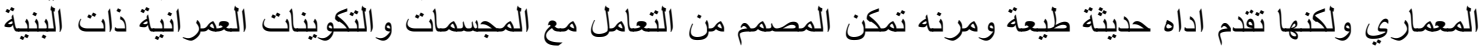
المعقدة وتتبع نظام تشكيلي ومعلوماتي، كما مكنت المصدم من محاكاه الطبيعة وفهم الأنظمة البنائية التي تقوم علئها

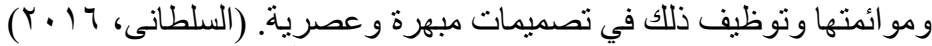

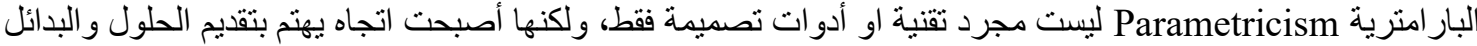

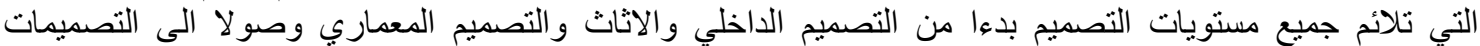


- ـ التقيبم الرقمي والقياس الكمي لمؤشر الراحة الحرارية داخل الفراغات العمرانبة من خلال برمجيات التصميم البار امتري التريمي r-1

اعتمد البحث في عمله على المناهج الآتية:

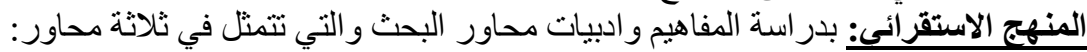

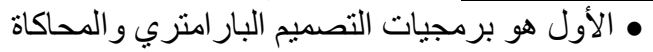
• • الثاني هو جودة الحياة البيئية

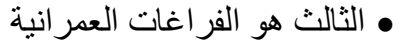

المنهج التحليلي: من خلال تحليل مصفوفة العناصر للمحور الأول و الثاني داخل برمجيات التصميم البار امترى و المحاكاة

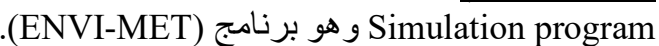

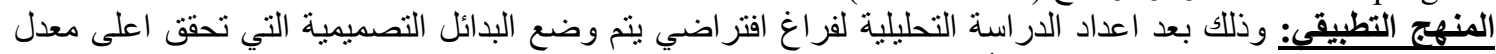

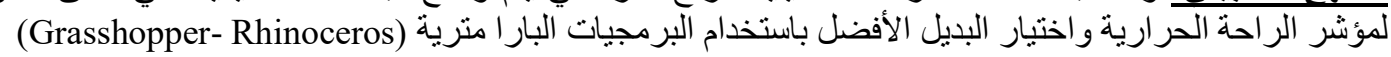

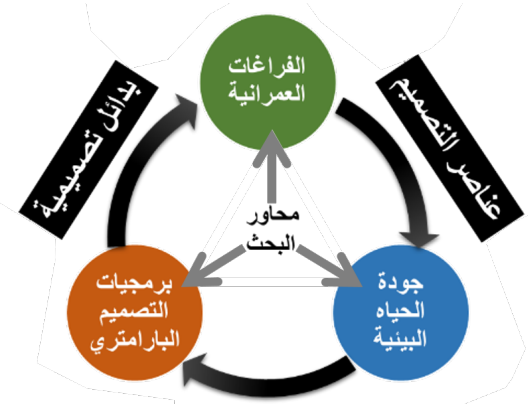

\section{مؤثــــــــرات}

شكل (1 ) محاور ومنهجية البحث(الباحث)

r بـ البار امترية والتصميم البارامتري(المحور الأول)

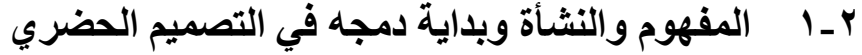

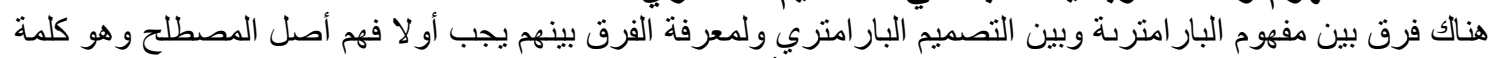

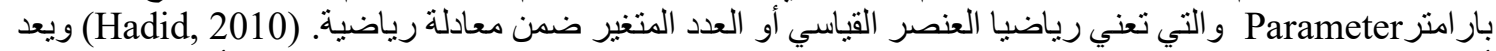
أي تغيير في قيمة هذا العنصر تؤثر على المعادلة الرياضية وتعطي نتائج مختلفة. فمثلا كما نعلم أن حجم متوازي

$\mathrm{H} * \mathrm{~W} *$ Volume of Rectangular Prism = L

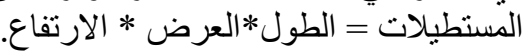
حيث يعتبر كل من الطول والعرض والارتفاع في هذه المعادلة عنصر اً قياسياً بار امترياً لأن أي تغيير في قيمة أحد هذه أنها

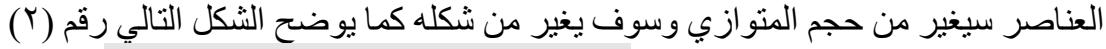

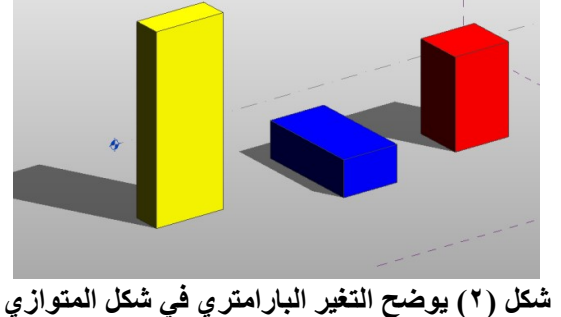

تعريف البارا مترية لغويا كلمة بار امتر Parameter هي كلمة يونانية مكونة من مقطعين الأول بار ا أب جانبي و الثاني متر أي القياس وتعنى

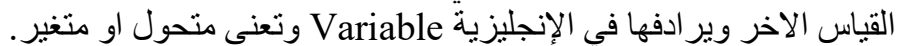

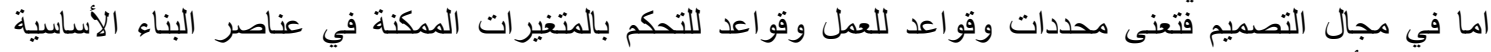

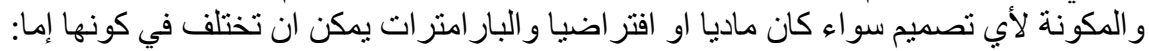

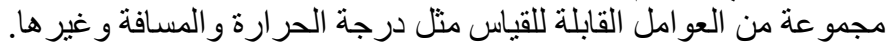

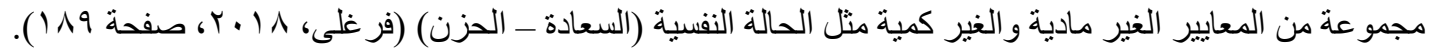




\section{تطبيق البرمجيات البارامترية لقياس الراحة الحرارية للفراغات العمرانية لتحسين مؤشرات جودة الحياة البيئية

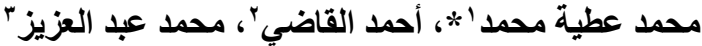

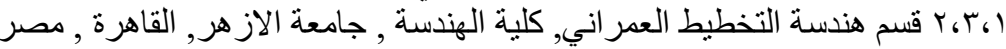 \\ E-mail attiaokla@gmail.com}

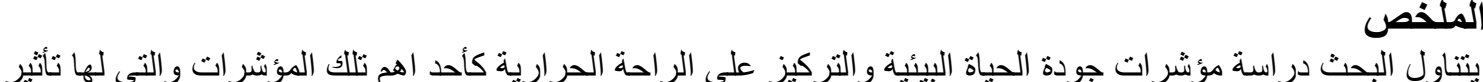

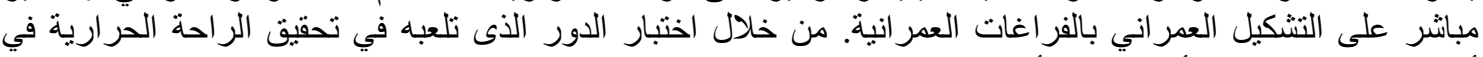

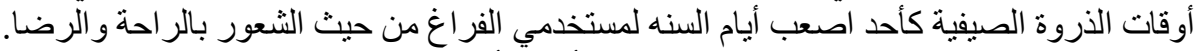

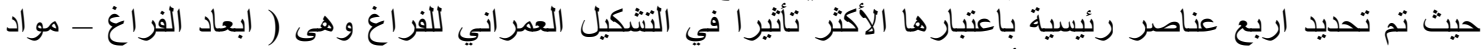

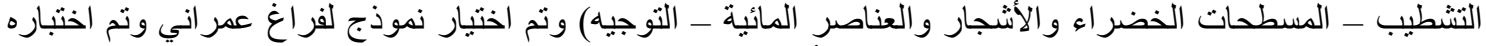

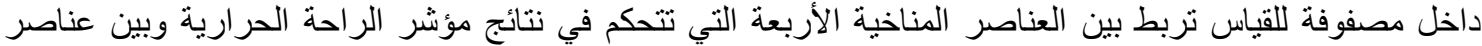

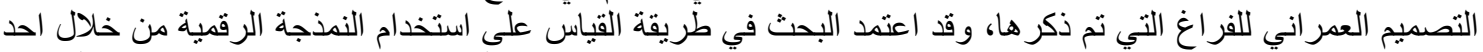
بر امج المحاكاة وقد تم اختيار ENVI-MET باعتباره احد البر امج المعتمدة في الأبحاث والتي التي تم اختبار التبار نتائجه و التأكد من

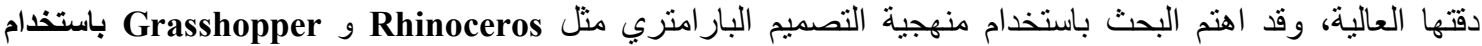
ENVI-MET plugin

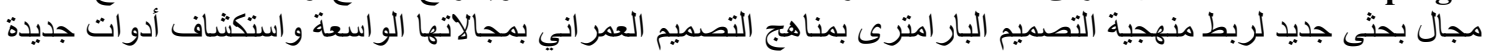
plugin داخل هذه البرمجيات للاستفادة منها.

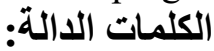

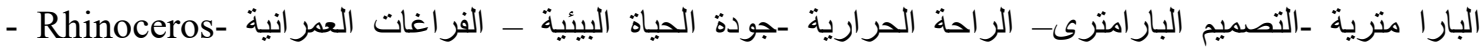
ENVI-MET plugin- Grasshopper

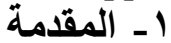

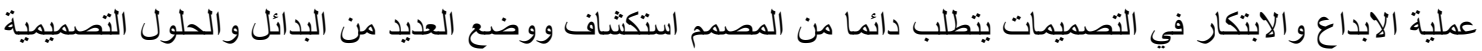

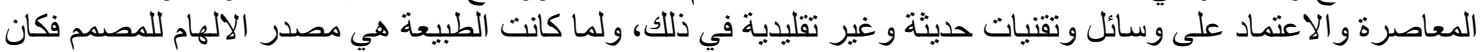

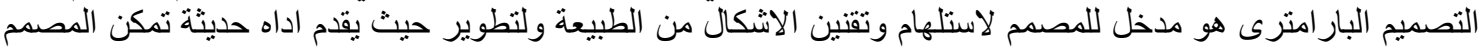

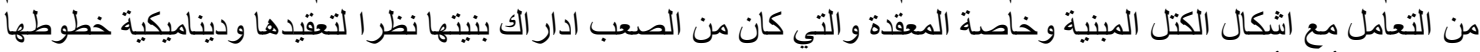

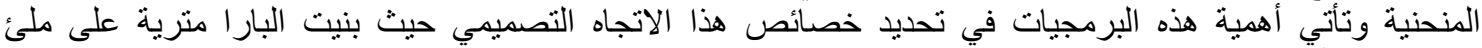

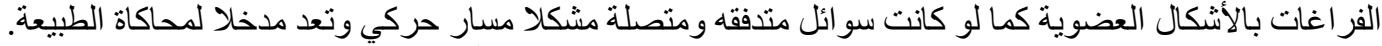

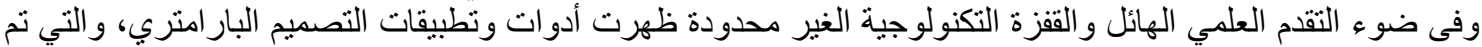

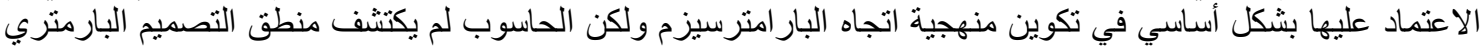

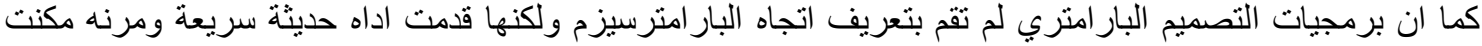

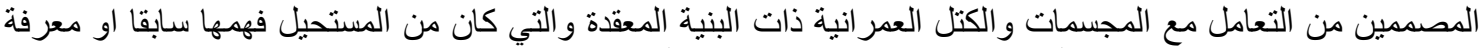

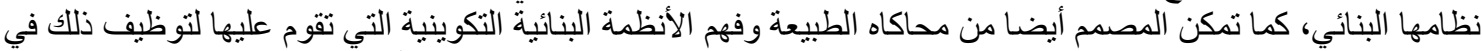

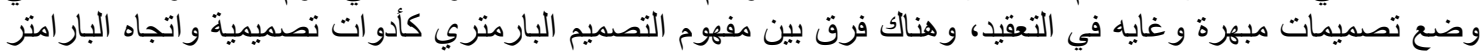

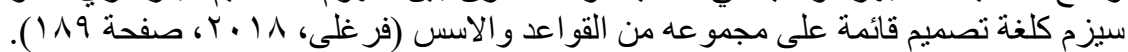

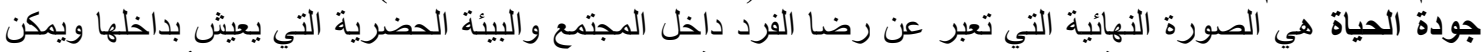

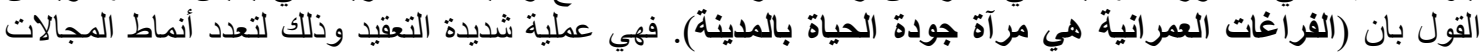

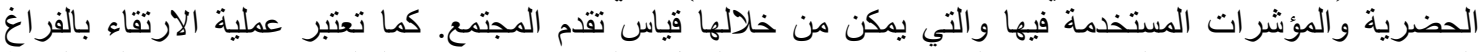

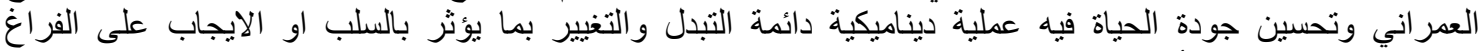

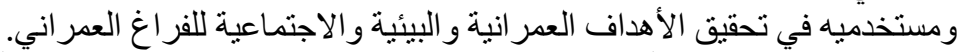

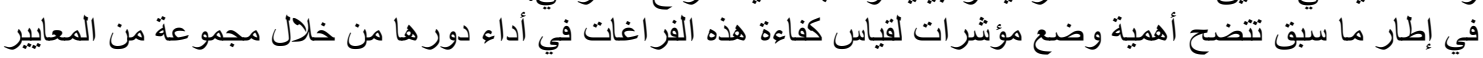

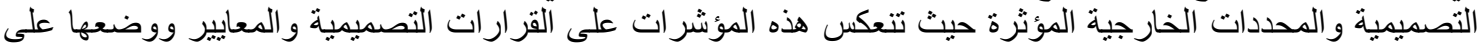
المسار الصحيح الذي يو اكب التغييرات العالمية.

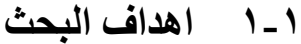

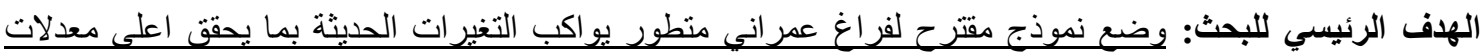

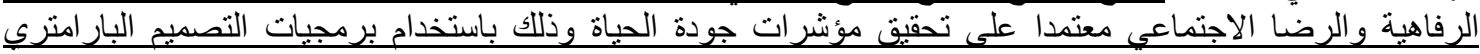
وبر امج المحاكاة كاداه تحليلية.

ولتحقيق هذا الهدف الرئيسي يمكن وضع مجموعة من العادية الأهداف الفرعية التي يحققها البحث:

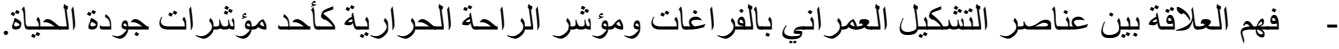




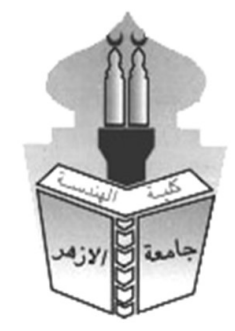

\title{
SPACES TO IMPROVE ENVIRONMENTAL QUALITY INDICATORS
}

\author{
Muhammad Attia Muhammad'*, Ahmed Al-kady², Mohammed Abdulaziz ${ }^{3}$ \\ ${ }^{1,2,3}$ Urban Planning Eng. Dept., Faculty of Engineering, Al-Azhar University, Cairo, Egypt. \\ E.MAILattiaokla@gmail.com
}

\begin{abstract}
The research deals with studying the indicators of environmental quality of life and focusing on thermal comfort as one of the most important indicators that have a direct impact on the urban formation in urban spaces. By examining the role, it plays in achieving thermal comfort at peak summer times as one of the most difficult days of the year for vacuum users in terms of feeling comfortable and satisfied.

Where four main elements were identified as being the most influential in the urban form of the space, (dimensions of space - materials - green spaces, trees and water elements orientation).

A model of urban space was chosen and tested within a measurement matrix linking the four climatic elements that control the results of the comfort index. The study relied on the measurement method on the use of digital modeling through one of the simulation programs, and ENVI-MET was chosen as one of the certified programs in the research whose results were tested and made sure of its high accuracy. Parametric design methodology such as Rhinoceros and Grasshopper using the ENVI-MET plugin by preparing spatial modeling within these applications, outputting, and analyzing the results. The research also opens a new field of research to link the parametric design methodology with urban design approaches in its wide fields and explore new tools plugin within this software to take advantage of them.
\end{abstract}

Key words:

Parametricm - Parametric Design - Thermal Comfort - Environmental Quality - Urban Spaces -Rhinoceros -Grasshopper - ENVI-MET plugin 